\title{
Forecasted deep stratospheric intrusions over Central Europe: case studies and climatologies
}

\author{
T. Trickl ${ }^{1}$, H. Feldmann ${ }^{2,}{ }^{*}$, H.-J. Kanter ${ }^{1}$, H.-E. Scheel ${ }^{1}$, M. Sprenger ${ }^{3}$, A. Stohl ${ }^{4}$, and H. Wernli ${ }^{3}$ \\ ${ }^{1}$ Karlsruher Institut für Technologie, Institut für Meteorologie und Klimaforschung (IMK-IFU), Kreuzeckbahnstr. 19, \\ 82467 Garmisch-Partenkirchen, Germany \\ ${ }^{2}$ Rheinisches Institut für Umweltforschung, Univ. zu Köln, Aachener Str. 201-209, 50931 Köln, Germany \\ ${ }^{3}$ Eidgenössische Technische Hochschule (ETH) Zürich, Institut für Atmosphäre und Klima, Universitätstr. 16, \\ 8092 Zürich, Switzerland \\ ${ }^{4}$ Norwegian Institute for Air Research, P.O. Box 100, Instituttveien 18, 2027 Kjeller, Norway \\ *now at: Karlsruher Institut für Technologie, Institut für Meteorologie und Klimaforschung (IMK-TRO), Postfach 3640, \\ 76021 Karlsruhe, Germany
}

Received: 8 September 2008 - Published in Atmos. Chem. Phys. Discuss.: 26 January 2009

Revised: 17 December 2009 - Accepted: 21 December 2009 - Published: 20 January 2010

\begin{abstract}
Based on daily predictions of stratospheric air intrusions, obtained from trajectory calculations by ETH Zürich with wind fields from ECMWF forecasts, a high number of measurements with the ozone lidar at IMKIFU (Garmisch-Partenkirchen, Germany) were carried out in 2001. The lidar measurements show a large variety of rather different cases reflecting the full complexity of intrusion episodes that is not visible in classical case studies. In part, tropopause folds could be fully captured. The frequency of intrusion cases forecasted and verified by vertical sounding or in the in-situ data recorded at the nearby Zugspitze summit (2962 m a.s.1.) exceed that in previous work by more than a factor of two. Three cases mapped with the lidar were selected to validate the results for the corresponding time periods extracted from a one-year run with the new hemispheric version of the chemistry-transport model EURAD. Due to the high spatial resolution chosen for these simulations the agreement with the lidar measurements is satisfactory. The Zugspitze ozone data from 1978 to 2004 were recently filtered by applying different criteria for stratospheric air, based on the ${ }^{7} \mathrm{Be}$ and humidity measurements. Here, by using the daily model forecasts during the time period 2001-2005, we examine three criteria and determine how well they represent the stratospheric air intrusions reaching the mountain site. Seasonal cycles for the period 2001-2005 were derived for
\end{abstract}

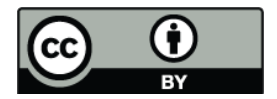

Correspondence to: $\mathrm{T}$. Trickl (thomas.trickl@kit.edu) the forecasts as well as the intrusion frequency per month for the forecasted intrusions and each of the criteria, distinguishing eight different characteristic transport pathways. In most cases a winter maximum and a summer minimum was obtained, but in the case of cyclonic arrival of intrusions starting over Greenland a late-spring maximum is seen. Two of the filtering criteria examined, based on combining a relativehumidity (RH) threshold of $60 \%$ with either a ${ }^{7} \mathrm{Be}$ threshold of $5.5 \mathrm{mBq} \mathrm{m}^{-3}$ or the requirement for $\mathrm{RH} \leq 30 \%$ within $\pm 6 \mathrm{~h}$, rather reliably predict periods of deep intrusions reaching the Zugspitze station. An "or" combination of both these criteria yields slightly more cases and covers $77.9 \%$ of the intrusions identified. The lack of observations in the complementary $22.1 \%$ are mostly explained by overpasses. In this way the long-term trend of stratospheric ozone observed at this site as well as the corresponding ozone budget may be derived on the basis of measurements only. This effort will be the subject of a subsequent publication.

\section{Introduction}

With the advent of quasi-continuous lidar remote sensing the investigation of stratosphere-to-troposphere transport (STT) has strongly revived (e.g., Browell et al., 1987; Ancellet et al., 1991; Langford et al., 1996; Ravetta et al., 1999; Eisele et al., 1999; Stohl and Trickl, 1999; Baray et al., 2000; Grant et al., 2000; Cho et al., 2001; Zanis et al., 2003; Trickl

Published by Copernicus Publications on behalf of the European Geosciences Union. 
et al., 2003; Galani et al., 2003; Flentje et al., 2005; Papayannis et al., 2005). The ability of the lidar method to generate vertically highly resolved dense time series yields complete or partial mappings of stratospheric air intrusions previously not that easily accessible. In this way also a valuable basis for the quality assurance of numerical models is established. In particular in the frame of the European (EU) projects VOTALP (Vertical Ozone Transport in the ALPS; VOTALP, 2000a, b) and STACCATO (Influence of Stratosphere-Troposphere Exchange in a Changing Climate on Atmospheric Transport and Oxidation Capacity; STACCATO, 2003, http://www.forst.tu-muenchen.de/EXT/ LST/METEO/staccato/) the lidar measurements and the continuous measurements at high-altitude Alpine summit stations have stimulated major efforts in model development, application and validation (e.g., Stohl and Trickl, 1999; Stohl et al., 2000; Zanis et al., 2003; Cristofanelli et al., 2003; Meloen et al., 2003; Roelofs et al., 2003). Many models are, still, far from being quantitative. This may, in part, be ascribed to insufficient spatial resolution, combined in Eulerian models with numerical diffusion, and problems in properly describing the free-tropospheric mixing. The meteorological fields provided, e.g., by the European Centre for MediumRange Weather Forecasts (ECMWF) underlying many of the simulations, in principle, capture stratospheric intrusions rather accurately (Zanis et al., 2003). However, vertical displacements with respect to the observed ozone structures in part visible in model results for the northern rim of the Alps suggest to improve the model orography, i.e., the horizontal resolution.

The vertical sounding activities within STACCATO (2000-2002) and the German follow-up project ATMOFAST (Atmospheric Long-range Transport and its Impact on the Trace-gas Composition in the Free Troposphere over Central Europe; ATMOFAST, 2005) were based on daily fourday trajectory forecasts by ETH (Eidgenössische Technische Hochschule) Zürich (Zanis et al., 2003). In this way, the measurements could be called for and synchronized in a highly systematic way. In Garmisch-Partenkirchen (Germany), particularly frequent lidar measurements were carried out during the period between February and August 2001, covering 20 of the 33 predicted STT events. This selection was mainly due to limiting the warnings at that time to sufficiently large direct intrusions reaching the majority of the partner stations. The measurements were, whenever possible, extended over several days which yielded a rich data set containing information on both STT and trans-Atlantic transport. A first case study was published by Zanis et al. (2003). In this study and in a companion paper on long-range advection of stratospheric air (Trickl et al., 2009) we give a more complete report of the results obtained in 2001 which cover a large variety of rather different situations.

Lidar measurements based on intrusion forecasts were started in Garmisch-Partenkirchen in 1996 (Eisele et al., 1999), initially using a "classical" approach previously derived for the intrusion forecast for the nearby mountain-top stations Zugspitze (2962 ma.s.l.) and Wank (1780 ma.s.l.) since the 1970s (e.g., Sladkovic and Munzert, 1990). This forecast method implied criteria such as the position and an anti-cyclonic bending of the jet stream and a potentialtemperature range typically between 295 and $305 \mathrm{~K}$, derived from extensive analyses of STT observations at the Zugspitze summit in the 1970s. A 98-\% probability of detecting at least one stratospheric air tongue at the Zugspitze summit during a predicted intrusion period was found from a comparison with the lidar measurements for the 23 months of investigation (1996-1997). The occasional discrepancies found in the 1990s were mostly limited to the warm season.

This approach obviously excludes layers from remote intrusions and, therefore, is not expected to yield a coverage of intrusion events as complete as the more recently used trajectory calculations by ETH Zürich based on ECMWF forecasts (see above). The more complete ETH forecasts have also opened the possibility of reviewing criteria for filtering the station data with respect to STT. Applying optimized filtering criteria to the almost continuous data series available for the two summit stations since the 1970s could lead to a quantification the stratospheric air reaching the respective altitudes in this area based on measurements alone.

There have been numerous attempts to estimate STT from experimental data (e.g., Danielsen and Mohnen, 1977; Viezee et al., 1983; Beekmann, et al., 1997; more information may be obtained from the references in these papers and in the general overview papers by Holton et al., 1996 and Stohl et al., 2003). Results from case studies or a large number of vertical profile measurements have been used and extrapolated to the Northern Hemisphere or the entire globe by using assumptions such as model-derived geographical distributions of the tropopause folding activity. Beekmann et al. (1997) analysed sonde data and selected relative-humidity (RH) thresholds of 20 or $25 \%$ together with ozone increases by at least $20 \%$ with respect to a climatological mean profile for their analysis of tropopause folds in the entire free troposphere. In addition, meteorological criteria such as the existence of a nearby uppertropospheric jet stream, a pronounced potential temperature gradient or elevated potential vorticity were included. This effort, extended to up to 26 years of sounding data, yielded an annual coverage by STT of 3 to 5\% for the free troposphere above western European stations as well as a rather constant seasonal cycle. A cross-tropopause ozone flux of $5.7 \times 10^{10}$ molecules $\mathrm{cm}^{-2} \mathrm{~s}^{-1}$ was estimated for the Northern Hemisphere and $1.2 \times 10^{11}$ molecules $\mathrm{cm}^{-2} \mathrm{~s}^{-1}$ for Western Europe.

A number of studies to assess the ozone budget for intrusions reaching $3000 \mathrm{~m}$ over Central Europe have already been carried out based on filtering Zugspitze data. For this station almost continuous measurements (24-h averages) of the isotope ${ }^{7} \mathrm{Be}$, formed in the stratosphere to about $67 \%$ (Lal and Peters, 1967), have been made since 1970 (e.g., Pötzl and 
Carnuth, 1966; Reiter et al., 1971). A threshold for the integrated specific activity of ${ }^{7} \mathrm{Be}$ of $8 \mathrm{mBq} \mathrm{m}^{-3}$ for unambiguous intrusions was recommended by Sladkovic and Munzert (1990), while Eisele et al. (1999) state that $5 \mathrm{mBq} \mathrm{m}^{-3}$ is already strongly indicative of a deep intrusion event. Other filtering criteria, further narrowing the STT time intervals, are based on significant drops in relative humidity and a simultaneous rise in ozone. Elbern et al. (1997) carried out a statistical analysis of the Zugspitze data with variable thresholds for the ten-year period 1984-1993. As a first step the correlated behaviour of ${ }^{7} \mathrm{Be}$, ozone and relative humidity was examined. In a second step the statistical significance of the identified potential intrusion events was calculated for an eleven-day period around each event and insignificant cases were excluded. For ${ }^{7} \mathrm{Be}$ and $\mathrm{O}_{3}$ thresholds of 2.9 and 2.1 times the standard deviation of the values with respect to the running monthly mean were chosen, respectively. In this way, 195 stratospheric intrusions could be unambiguously identified for the Zugspitze summit, 85 of which were also observed at the lower-lying Wank station. A seasonal cycle of the stratospheric fraction of the Zugspitze ozone with a winter maximum and a summer minimum was determined.

In a rather thorough study Stohl et al. (2000), again, analysed the Zugspitze data (1991-1997) as well as those from the VOTALP partner stations Jungfraujoch (3580 m a.s.l.), Sonnblick (3106 m a.s.1.) and Monte Cimone (2165 m a.s.1.) for a more confined period of two to three years. A sensitivity study for the Zugspitze data showed that the results strongly depend on the thresholds for the data filtering when going from the selection criteria $\left[{ }^{7} \mathrm{Be}\right]>10 \mathrm{mBq} \mathrm{m}^{-3}$ and $\mathrm{RH}<30 \%$ to $\left[{ }^{7} \mathrm{Be}\right]>6 \mathrm{mBq} \mathrm{m}^{-3}$ and $\mathrm{RH}<30 \%$. No proof of the predominantly stratospheric nature of the air corresponding to the less critical thresholds was given, which is an important topic of the investigations presented here. In addition to the filtering of the station data, a three-year run (January 1995-September 1997) with the FLEXPART tracer model was carried out which yielded a direct comparison of the four stations as well as the influence of the tropospheric age of the stratospheric air tongues on the seasonal cycle (model domain: $50^{\circ} \mathrm{W}$ to $50^{\circ}, \mathrm{E}, 25^{\circ} \mathrm{N}$ to $80^{\circ} \mathrm{N}$ ). The results for a calculation subsequently extended to the years 1995-1999 are shown in Fig. 1. The seasonal cycle published by Elbern et al. (1997) for the Zugspitze summit is qualitatively confirmed, but both analyses for the late 1990s (station and model), exhibit a more pronounced summer minimum. The summer minimum is less pronounced at the higher-lying Jungfraujoch than at the other three stations, and, thus, the seasonal cycle resembles more that obtained by Beekmann et al. (1997) for the entire free troposphere.

The FLEXPART results for the Zugspitze summit suggest an annual average of about $4.2 \mathrm{ppb}$ (about $8.4 \%$ of the annual average ozone) of ozone originating in deep intrusions reaching $3000 \mathrm{~m}$ in that area. As will be shown in this study the FLEXPART model domain chosen is too small to cover all relevant source regions of STT. Nevertheless, the

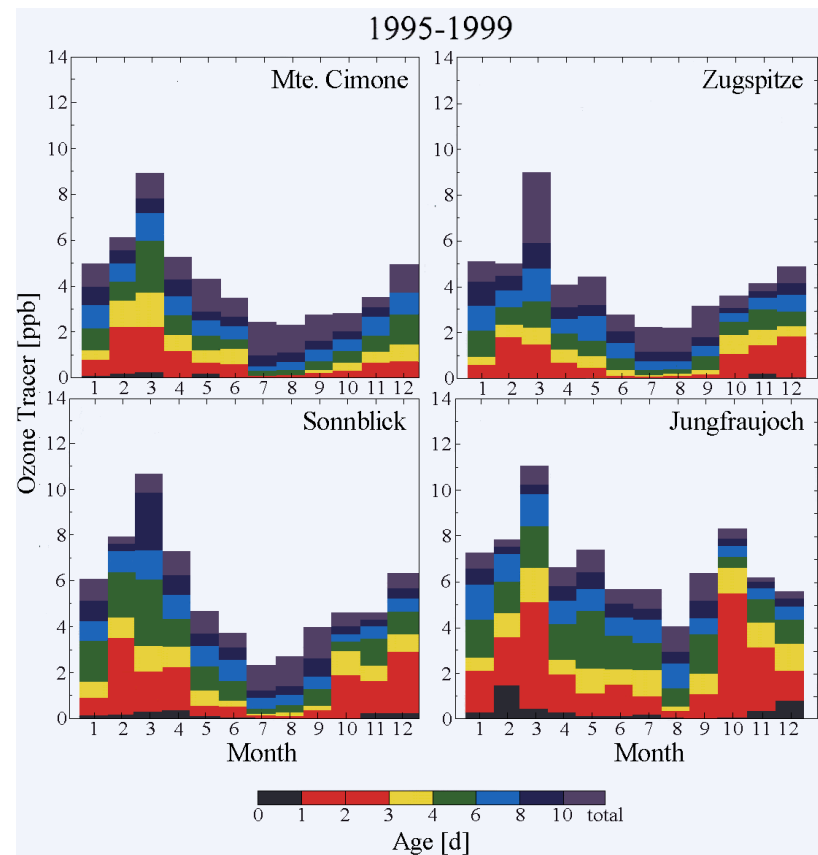

Fig. 1. Monthly mean values of the ozone mixing ratio obtained from of a five-year run with the FLEXPART model (1995-1999) for stratospheric tracers arriving at the four VOTALP summit stations Monte Cimone, Zugspitze, Sonnblick and Jungfraujoch; the tropospheric age of the tracers is colour coded. The tracers were released in a limited domain covering Europe and the North Atlantic Ocean. The summer minimum at the higher Jungfraujoch station is less pronounced than at the three other, lower-lying sites. For more details see (Stohl et al., 2000).

FLEXPART result was approximately confirmed in more recent re-analyses of the Zugspitze data by Scheel (Scheel, 2003; ATMOFAST, 2005) yielding 8.8\% (4.4 ppb) of stratospheric ozone contribution per year. However, the analysis of the station data was based on a restrictive threshold for ${ }^{7} \mathrm{Be}$ (85th percentile, which coincides with $8 \mathrm{mBq} \mathrm{m}^{-3}$ in the late 1990s; see also (Cristofanelli et al., 2006) for a similar approach for the partner station Mte. Cimone in Italy). Furthermore, a positive trend of STT ozone reaching the Zugspitze summit was found. The ${ }^{7} \mathrm{Be}$ data suggest a start of that increase in the mid-seventies (Scheel and Kanter, 2002).

In this paper, we give a final summary of the observations of STT events within STACCATO and ATMOFAST, in relation to the forecasts. In particular, we discuss (as mentioned) the most interesting examples from the very successful lidar sounding period 2001, including additional analyses with the FLEXPART and EURAD models for further clarification. Vice versa, the measurements made possible by the forecasts yield ideal material for the validation of the new hemispheric version of EURAD. In addition, based on the forecast data, we address the important question of how many of the predicted stratospheric air intrusions descend to the Alpine summit levels here represented by the Zugspitze 
station (2962 m a.s.l.). This effort, in turn, also confirms the excellent quality of the forecasts. Furthermore, the forecasts serve as a referee to judge the existing and new approaches for identifying the presence of stratospheric air based on correlating complementary station data. We also give some statistical analysis (2001-2005) for the most important transport pathways and their relative impact on the observations at this Alpine site.

\section{Methods}

\subsection{Ozone lidar}

The tropospheric ozone lidar at IMK-IFU $\left(47^{\circ} 28^{\prime} 37^{\prime \prime} \mathrm{N}\right.$, $11^{\circ} 3^{\prime} 52^{\prime \prime} \mathrm{E}, 740 \mathrm{~m}$ a.s.l.) was completed in its first version in 1990 (Kempfer et al., 1994) and upgraded in 1994 and 1995 (Eisele and Trickl, 1996; 2005). It has a unique vertical range between $0.2 \mathrm{~km}$ and roughly $15 \mathrm{~km}$ above the ground, features low uncertainties of accuracies of about $\pm 3 \mathrm{ppb}$ in the lower troposphere and $\pm 6 \mathrm{ppb}$ (under optimum conditions) in the upper troposphere. The upper-tropospheric performance may be degraded in the presence of high lowertropospheric ozone concentrations absorbing a lot of the ultraviolet laser emission and by enhanced sky light in summer, in particular in the presence of clouds. The vertical resolution is dynamically varied, roughly between $50 \mathrm{~m}$ and a few hundred metres, depending on the signal-to-noise ratio that decreases with altitude. The lidar has been used in numerous investigations mostly focussing on atmospheric transport (e.g., Eisele et al., 1999; Stohl and Trickl, 1999; Seibert et al., 2000; Carnuth et al., 2002; Trickl et al., 2003; Zanis et al., 2003).

\subsection{Zugspitze series}

For the identification of stratospheric intrusions at the Zugspitze station (summit: $2962 \mathrm{~m}$ a.s.l., located $8 \mathrm{~km}$ to the south west of IMK-IFU) half-hourly averages of ozone, carbon monoxide and relative humidity (RH) as well as 24-h averages of the isotope ${ }^{7} \mathrm{Be}$ have been used. The ${ }^{7} \mathrm{Be}$ series at the Zugspitze is the longest and goes back to 1970 (e.g., Pötzl and Carnuth, 1966; Reiter et al., 1971; Scheel and Kanter, 2002; Zanis et al., 2003a; Tositti et al., 2004). Ozone has been measured since 1978 (e.g., Reiter et al., 1987; Scheel et al., 1997; Oltmans et al., 2006). A chemiluminescence instrument (Bendix Corporation, model 8002) was in operation until 1999 . Thereafter, only ultraviolet absorption instruments have been employed (Thermo Electron, TE49 analysers). Carbon monoxide has been measured since 1990, using instrumentation based on gas chromatography with a mercury reduction detector (Trace Analytical, RGD2) or gas filter correlation infrared absorption (Thermo Electron, TE48S) as well as vacuum resonance fluorescence (AL5001, AeroLaser, Germany), with two different systems running in parallel for most of the time. $\mathrm{RH}$ is measured with a dew-point mirror (Meteorolabor, Thygan VTP6) with an uncertainty below 5\% RH.

\subsection{Forecasts}

The stratospheric intrusion forecasts, based on operational ECMWF forecasts, have aided the STACCATO measurement groups with the set-up and planning of the observations. Every twelve hours four-day forward trajectories were calculated with the Lagrangian Analysis Tool (LAGRANTO; Wernli and Davies, 1997), starting in the entire region covering the Atlantic Ocean and Western Europe $\left(20^{\circ} \mathrm{E}\right.$ to $80^{\circ} \mathrm{W}$ and $40^{\circ}$ to $80^{\circ} \mathrm{N}$ ) between 250 and $600 \mathrm{mbar}$. From this large set of trajectories those initially residing in the stratosphere (potential vorticity larger than $2 \mathrm{pvu}$ ) and descending during the following four days by more than $300 \mathrm{mbar}$ into the troposphere were selected as "stratospheric intrusion trajectories". The same selection criterion was used in a previous case study (Wernli, 1997) to study an intrusion associated with a major Atlantic cyclone. A first case study based on the forecast was described by Zanis et al. (2003).

These forecasts, daily distributed by automatically generated e-mail messages, have been made available almost continuously since November 2000, with only less than 3\% missing in the five years selected for our analysis (20012005). Since June 2001 so-called "intrusion hit tables" were additionally distributed giving a crude estimate of the timeheight development of stratospheric air above the four partner stations Jungfraujoch, Zugspitze, Monte Cimone and Thessaloniki over several days.

For the analysis of a specific intrusion event the entire sequence of daily generated forecast plots showing the relevant intrusion(s) were examined. On each day, forcasts are calculated for the start times 00:00 and 12:00 UTC, as well as for 00:00 and 12:00 UTC on the following day. We examined the entire sequence of trajectory plots showing a specific STT event. Due to the daily changing ECMWF forecast data there are differences between the trajectory plots for the same start time, but generated on subsequent days, in particular variations in the positions of the source regions. These differences become less important when the trajectory bundles approach Europe. The bundles are usually wide enough for reliable predictions of observing intrusions with the lidar or at the Zugspitze summit. However, due to the coarse vertical and temporal resolution of the graphical representations the forecasts could only be used to identify the presence of stratospheric air above the Garmisch-Partenkirchen area. For more refined analyses additional trajectory or model calculations were made (see below and Sect. 2.4).

For the analysis of the Zugspitze series (2001-2005, see Sect. 5) extensive trajectory calculations were carried out with the HYSPLIT model whenever the measurements indicated an intrusion not clearly identified by the forecasts. This was the case when the intrusions started outside the ETH model domain or when the transport time exeeded four days. 
The advantage of this approach is that HYSLPIT can be promptly operated via the internet on a server of the National Oceanic and Atmospheric Administration (http://www.arl. noaa.gov/ready/hysplit4.html; Draxler, 1998), which helped us to save a lot of time in this considerable effort. The trajectories were calculated with archived NCAR/NCEP reanalysis data and extended $315 \mathrm{~h}$ backward in time (maximum time span allowed). Several initial height levels were chosen ( $3000 \mathrm{~m}$ and higher) since $3000 \mathrm{~m}$ a.s.l. is obviously converted into a wrong relative height above the ground (see example in Fig. 2), presumably due to a crude orography of the underlying data field not resolving the altitudes of IMKIFU $(730 \mathrm{~m})$ and the nearby Zugspitze $(2962 \mathrm{~m})$. Also, in many cases trajectories were calculated for times adjacent to a pronounced humidity dip in order to make sure that there are no temporal shifts. An air mass reaching the summit station was accepted as significantly stratospheric when at least one HYSPLIT trajectory reached or exceeded an altitude of roughly $8 \mathrm{~km}$ at sufficiently high latitudes (and depending on the season) where one could expect the tropopause. Although comparisons with successful ETH forecasts indicate that our approach is rather robust some uncertainty remains since HYSPLIT does not yield potential vorticity. However, it is important to note that most contributions from outside the ETH model domain come from the colder seasons during which a lower tropopause height may be assumed. In some cases the HYSPLIT trajectories overlapped with trajectory bundles of earlier ETH forecasts not reaching GarmischPartenkirchen within their four-day time span. These cases, sometimes related to STT events even more than 10 days backward in time, were a posteriori accepted as successful forecasts.

The analysis covers all cases either forecasted by the four-day trajectories, with the exception of intrusions originating roughly $1000 \mathrm{~km}$ and less away from GarmischPartenkirchen because they do not have a chance to subside to $3000 \mathrm{~m}$, and all cases additionally identified from the observations and verified by HYSPLIT calculations. Therefore, we missed stratospheric air masses from either outside the ETH model domain or from inside the domain, but with a travel time of more than four days, do not enter our count if they overpass the station at altitudes high enough that there is no indication in the Zugspitze record. As shown in our long-range transport studies there may be considerable advection of thick aged air layers, rapidly travelling in the middle and upper troposphere, fed by STT events above the Pacific Ocean and Asia (Trickl et al., 2003, 2009).

\subsection{Models used for the analysis}

Details on individual intrusions cannot be fully analysed by the comparison of the forecast trajectory plots with the measurements due to the limited altitude and time information of these plots. Therefore, in part, additional calculations were made with the two models used within ATMOFAST.

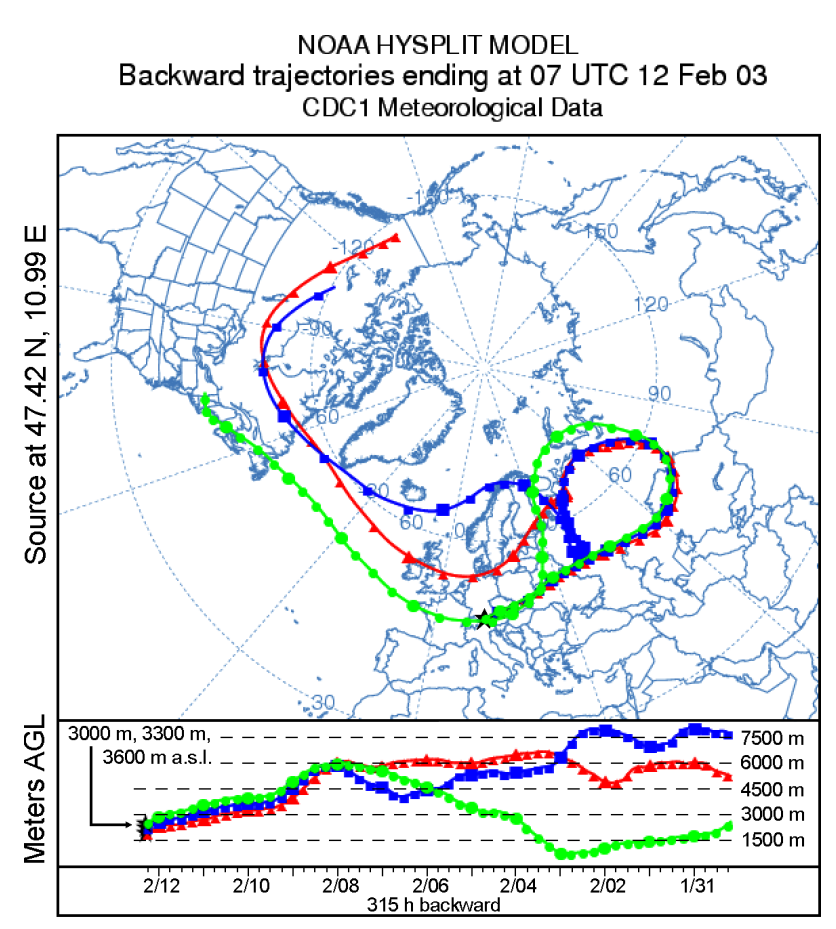

Fig. 2. 315-h backward trajectories started above the Zugspitze for the three altitude levels $3000 \mathrm{~m}$ (red triangles), $3300 \mathrm{~m}$ (blue squares) and $3600 \mathrm{~m}$ a.s.l. (green circles), calculated with the HYSPLIT model: The heights in the figure are given with respect to the ground (AGL) and are obviously wrong for the Zugspitze position (asterisk) due to an insufficient model orography. Thus, the exact height representing the Zugspitze summit is not certain. The air mass for the blue trajectory ( $3300 \mathrm{ma.s.1}$ ) started at almost $8 \mathrm{~km}$ above north-western Canada at $-315 \mathrm{~h}$ and proceeded as far east as West Siberia before it descended back to the observational site.

Some details have been evaluated with the FLEXPART tracer model (Stohl et al., 1998, 2005; Stohl and Thomson, 1999), operated with ECMWF re-analysis data. This model has been extensively used for transport studies, in particular for several STT case studies of our team (Stohl and Trickl, 1999; Stohl et al., 2000; Trickl et al., 2003, 2009; Zanis et al., 2003).

With the exception of the example discussed by Zanis et al. (2003) the FLEXPART analyses made for the cases described in Sect. 3 were made in the retroplume mode described by Stohl et al. (2002) and also in our parallel paper (Trickl et al., 2009). The backward plumes, calculated over twenty days, yield a more complete and reliable picture of the principal pathways of the air masses arriving at an observational site than conventional trajectory analyses since the full contour of the plume is obtained. Numerical particles were released in 250-m bins above Garmisch-Partenkirchen, up to $10 \mathrm{~km}$ a.s.l. Important for the investigations in this paper are the options showing the average horizontal and vertical positions and the fraction of numerical particles travelling in the stratosphere on a given day. A potential-vorticity threshold 
of 2 pvu was selected for identifying stratospheric air. Occasionally, we also inspected the fraction of particles with boundary-layer contact in order to get some idea of the mixing with tropospheric air suggested by the model runs.

The EURAD model, in contrast to the Lagrangian FLEXPART model, uses an Eulerian approach to study the origin and pathways of stratospheric air intrusions and intercontinental transport events. EURAD consists of the meso-scale meteorological model MM5 (Grell et al., 1994), the EURAD CTM (Hass et al., 1993) and the EURAD emission model (Memmesheimer et al., 1991). The model has been adapted to the tropopause and free tropospheric conditions (KowolSanten et al., 2000).

In view of the long-range transort studies within the ATMOFAST project, the EURAD model was extended from a regional to a hemispheric model. This effort was also motivated by the idea of obtaining better boundary conditions for more quantitative regional air-quality forecasts. The model version was optimized to run on a small-size PC cluster. A polar-stereographic projection centred at the north-pole is used. For the long-term model run described in this paper, requiring a considerable computation time, a compromise was chosen for the spatial resolution. The horizontal grid distance was increased to $125 \mathrm{~km}$, in the vertical 27 layers from the surface ( 937 mbar for the lidar location) up to a pressure level of $30 \mathrm{mbar}$ were selected. The vertical resolution varies between $10 \mathrm{mbar}$ next to the ground and $40 \mathrm{mbar}$ in the uppermost troposphere. GFS (Global Forecast System) analysis data are used as initial and boundary values for 24-hourly consecutive forecasts of MM5. The emissions were derived from the EDGAR 3.2 inventory.

The first hemispheric simulation with EURAD was performed for a well-documented STT event coinciding with the observation of ozone import from North America to Europe that took place by the end of May 1997 (Eisele et al., 1999; Stohl and Trickl, 1999). The ozone profiles calculated for Garmisch-Partenkirchen agree well with the lidar observations at IMK-IFU (ATMOFAST, 2005).

Single episodes and longer periods have been studied with this modified version of EURAD (e.g., Ebel et al., 2008). In particular, a full-year run was completed for 2001. The co-ordinated vertical sounding effort during that year, made possible by the daily forecasts, thus, offered a unique chance for a model validation. Two intrusion examples extracted from the run for 2001 are shown in this paper, one more also discussed in the companion paper (Trickl et al., 2009) is just briefly described. By comparison with the lidar measurements the quality of the simulations could be verified.

\section{Classification of the stratospheric air intrusions reaching the Northern Alps}

The forecast trajectories and the additional backward analyses revealed a number of different source regions of the intrusions as well as different pathways. This suggested a classification based on these criteria. These categories are also used for a detailed analysis of the intrusions observed at the Zugspitze summit presented in Sect. 5.2:

- Type 1: The intrusion originates in the region covering Greenland, Iceland and the adjacent part of the North Atlantic and anti-cyclonically or almost straightly approaches the Bavarian Alps (e.g., Fig. 8 in Sect. 3.9). Type 1 also comprises a few exotic cases of anticyclonic long-range descent via Russia.

- Type 2: The intrusion originates over Greenland or slightly to its east and proceeds to Western Europe or the Atlantic off the European or African coast; the final advection to Garmisch-Partenkirchen is cyclonic (e.g., 15 May and 18 July panels in Fig. 3). In some cases, the distinction between Type 1 and Type 2 is rather difficult.

- Type 3: Direct advection from source regions over Scandinavia or the North Sea.

- Type 4: Advection from the Atlantic to the south of Greenland and Iceland, but typically above $45^{\circ} \mathrm{N}$.

- Type 5: Advection from Canada and the adjacent part of the Polar Sea to the east of $80^{\circ} \mathrm{W}$ (i.e., within the range of the ETH forecast).

- Type 6: Westerly advection from Canada to the west of $80^{\circ} \mathrm{W}$, Alaska, Siberia and the adjacent parts of the Pacific and Polar Sea (i.e., outside the range of the ETH forecast); in this case, HYSLPIT backward trajectories were used for the analysis in Sect. 5.2.

- Type 7: Advection from the Atlantic with initial latitudes below $45^{\circ} \mathrm{N}$; this separation from Type 4 was made by intuition since this sector belongs to latitudes below that of the observational site.

- Type 8: Easterly to north-easterly advection from Russia, Siberia and the adjacent part of the Polar Sea; here, HYSPLIT trajectories were exclusively used for estimating the presence of stratospheric air.

Types 1, 2 and 3 comprise mostly direct intrusions, defined by reaching our observational area on an almost straight path within typically two or three days. These cases are related more to situations of anti-cyclonic or upcoming anti-cyclonic advection. However, in a number of (indirect) cases, these types may also involve longer advection paths or travel times. 

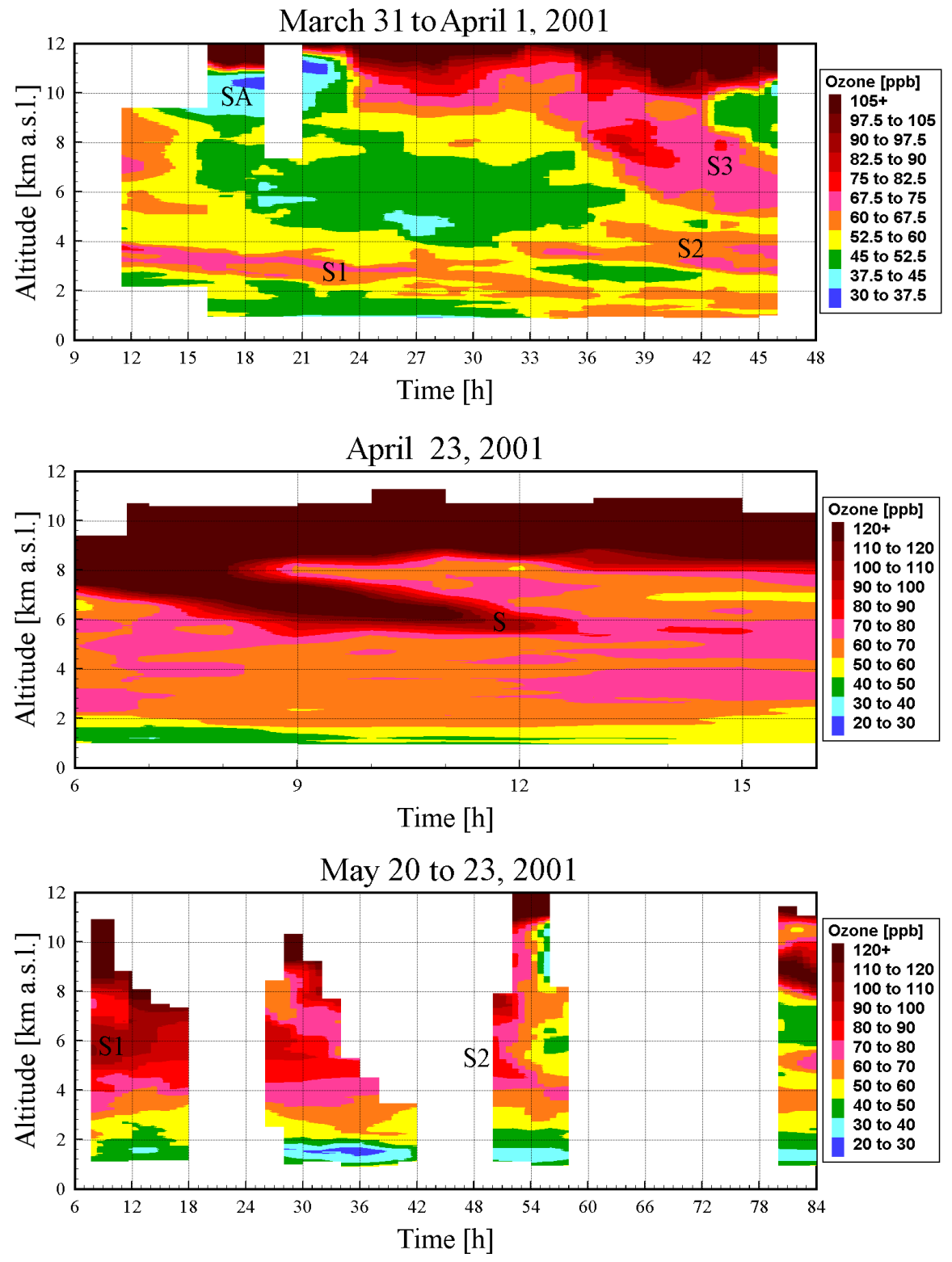

Fig. 3. Examples of lidar sounding series selected from the measurements in 2001; the labels S, S1, S2 and S3 denote stratospheric intrusions, LA means long-range advection from high altitudes over the North Pacific, SA ("subtropical Atlantic"), USA air from the boundary layer of the United States, P ("Pacific") advection from the Pacific Ocean and beyond. The time scale is given in Central European Time (=UTC+1 h).

Types 4, 5 and 6 are frequently related to situations with cyclonic or almost zonal advection, implying subsidence far to the west of Europe. We have named Types 4 to 6 indirect intrusions because of the longer travel time and path. Types 7 and 8 are special cases that are listed for the case of completeness, but are too rare to be evaluated statistically. This kind of classification should be relevant for a major part of Central Europe.

The distinction of cases is sometimes rather difficult. In a few cases rather exotic pathways were found, an example is shown in Fig. 2 (12 February 2003). The trajectory in
Fig. 2 reaches the highest altitudes at almost $8 \mathrm{~km}$ above the ground over north-western Canada $315 \mathrm{~h}$ backward in time. This case is very difficult to assign (Types 3, 5, 6 or 8 ), since the local tropopause height along the path is not known. Although the highest altitude was reached over Labrador similar altitudes were also calculated for Northern Finland. Here, the final descent starts which suggests to assign the case to Type 3. However, for earlier arrival times Type 5 looks more favourable and was chosen for the full period. 

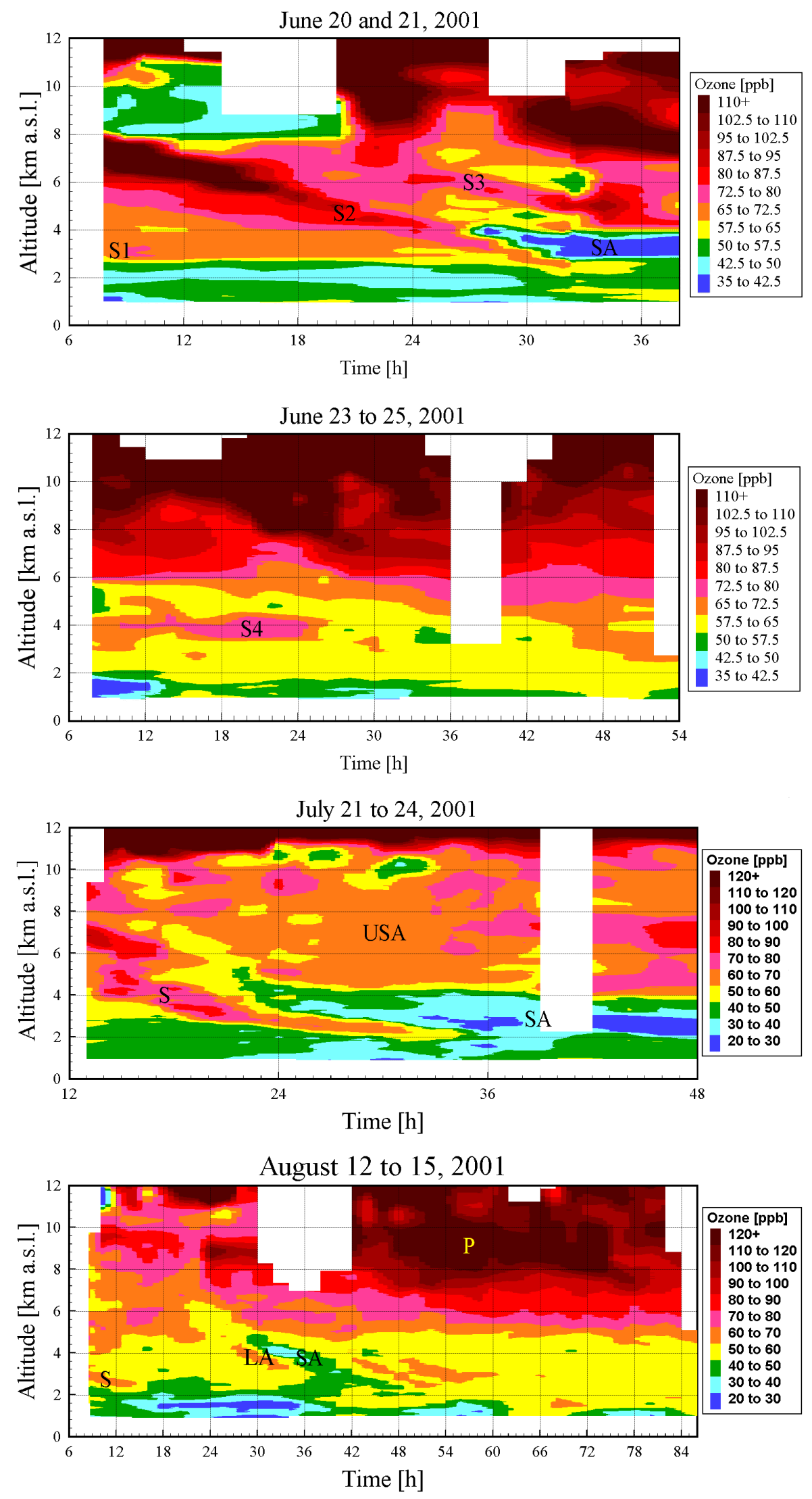

Fig. 3. Continued. 
Table 1. List of intrusion periods during the period of intensive lidar measurements between 10 February and 23 August 2001: The intrusion type is specified as defined in Sect. 3. For the Zugspitze data the days are listed on which one of the stratospheric criteria specified in Sect. 5.1 was met. For the lidar the number of observations on days with positive predictions is given.

\begin{tabular}{|c|c|c|c|c|}
\hline Predicted & Type & Zugspitze & Lidar Meas. & Comment \\
\hline $11-12$ Feb & 4 & $11-12 \mathrm{Feb}$ & 24,17 & \\
\hline $14-16$ Feb & 1 & $14 \mathrm{Feb}$ & $0,13,0$ & $14 \mathrm{Feb}:$ fog in valley \\
\hline $18 \mathrm{Feb}$ & 5 & $18 \mathrm{Feb}$ & 9 & \\
\hline $19 \mathrm{Feb}$ & 1 & $19 \mathrm{Feb}$ & 8 & \\
\hline $21 \mathrm{Feb}$ & 1 & 21 Feb (short) & n.m. & fog in valley \\
\hline $25-28 * \mathrm{Feb}$ & 2 & 27 Feb (short) & $4,5,22,5$ & mostly above Zugspitze \\
\hline 5-7 Mar & 2 & $6 \mathrm{Mar}$ & n.m. & no full hit pred., long path \\
\hline 13 Mar & 4 & n.d. & 4 & lidar: elevated $\mathrm{O}_{3}>5 \mathrm{~km}$ \\
\hline 16 Mar & 4 & c.n.f.m. & 5 & lidar: elevated $\mathrm{O}_{3}>5 \mathrm{~km}$ \\
\hline 24 Mar & 5 & c.n.f.m. & n.m. & {$\left[{ }^{7} \mathrm{Be}\right] \approx 7 \mathrm{mBq} \mathrm{m}^{-3}$} \\
\hline 28-29 Mar & 5 & c.n.f.m. & n.m. & \\
\hline 31 Mar-2 Apr* & $4,5,6$ & 2 detected & $10,22,1$ & 3 simultaneous intrusions \\
\hline $5 \mathrm{Apr}$ & 5 & c.n.f.m. & n.m. & {$\left[{ }^{7} \mathrm{Be}\right] \approx 5 \mathrm{mBq} \mathrm{m}^{-3}$} \\
\hline $14-15 \mathrm{Apr}$ & 1 & n.d., RH100 \% & n.m. & clearing too short \\
\hline $23 \mathrm{Apr}$ & 2,3 & first intr. seen & 13 & \\
\hline $24 \mathrm{Apr}$ & 4 & $24 \mathrm{Apr}$ & n.m. & \\
\hline $25 \mathrm{Apr}$ & 4 & c.n.f.m. & n.m. & \\
\hline $27 \mathrm{Apr}$ & 5 & $27 \mathrm{Apr}$ & n.m. & \\
\hline 2 May & 2 & 2 May & n.m. & highly indirect (Morocco) \\
\hline missed & 1 & 13 May & n.m. & \\
\hline 19-21 May & 2 , & 19-22 May & $6,8,9$ & \\
\hline 22 May & 1 & 22 May & 5,3 & lidar: 22-23 May \\
\hline $4-5$ Jun & 2,2 & 4-5 Jun & $7,12,3$ & 2 parallel intrusions \\
\hline 12-13 Jun & 2 & 12-13 Jun & $2,13,6$ & lidar: 11-13 Jun \\
\hline 15 Jun & 4 & 15 Jun (short) & n.m. & {$\left[{ }^{7} \mathrm{Be}\right] \approx 8.5 \mathrm{mBq} \mathrm{m}^{-3}$} \\
\hline 20-21 Jun $(2 \text { of } 3)^{*}$ & $6,1,1$ & first two seen & 8,9 & \\
\hline 23-24 Jun & 2 & 24 Jun & 9,12 & \\
\hline 25 Jun & 3 & 26-27 Jun & 4 & \\
\hline 2-3 Jul & 1 & $3 \mathrm{Jul}$ & 4,7 & lidar: 3-5 Jul \\
\hline 21-22 Jul & 2 & $22 \mathrm{Jul}$ & $10,20,12,4$ & lidar: 21-24 Jul \\
\hline $31 \mathrm{Jul}$ & 3 & $31 \mathrm{Jul}$ & n.m. & \\
\hline 2 Aug & 4 & 2 Aug & n.m. & \\
\hline $12-13$ Aug ( 1 of 2$)$ & 1 & 2 seen & $9,12,12,8$ & lidar: $12-15$ Aug \\
\hline $22-23$ Aug & 4 & 4 RH dips on 24-27 Aug & 13,3 & {$\left[{ }^{7} \mathrm{Be}\right]>5.5 \mathrm{mBq} \mathrm{m}^{-3}$ on $24-27 \mathrm{Aug}$} \\
\hline
\end{tabular}

* denotes cases for which the lidar revealed a high overpass.

Abbreviations: n.d. (not detected), c.n.f.m. (criteria not fully met), n.m. (no measurements).

\section{Case studies}

The forecasts made possible a very dense lidar sounding period in 2001 (11 February to 23 August, ended by a major laser damage). As mentioned in the introduction, measurements were made during 20 of the 33 predicted intrusion periods (see Table 1). Some of the periods were missed, mostly due to limiting the STACCATO warnings in autumn 2000 and 2001 to direct intrusions covering more than a single station, but also in two cases due to unfavourable meteorological conditions. During 26 of the predicted intrusion periods at least one stratospheric air tongue was verified at the summit station (column 3 of Table 1). In one case with very pronounced $\mathrm{O}_{3},{ }^{7} \mathrm{Be}$ and $\mathrm{RH}$ signature (13 May) the corresponding intrusion was predicted to pass more to the east (outside
Germany), but a HYSPLIT run indicates that it also reached our site. Table 1 also lists the intrusion type according to a classification described in Sect. 3 (column 2).

In this section we briefly present the lidar ozone series for six of the most interesting intrusion periods in 2001 (two additional extended time series are included in the final report of ATMOFAST, 2005). These examples not only document a large variety of rather different stratospheric air intrusion cases, but also their complexity. This complexity is reflected both by the detailed structure of individual intrusions and the co-existence of several different intrusions during a time period of just a few days, a rather frequent feature that has not been paid much attention to previously. Although we are far from understanding the details for this kind of intrusion clustering over the North Atlantic, it must to some extent be taken 
into account when analysing the observations at the Alpine summit stations as discussed in Sect. 5.

Among the examples shown are the first cases for which the early phase of a tropopause folding event was caught by our lidar. Airborne lidar measurements have yielded complete mappings of tropopause folds (e.g., Browell et al., 1987; Grant et al., 2000; Flentje et al., 2005). This is much more difficult for ground-based lidar measurements due to the fact that the stratospheric air tongues eventually reaching Europe start to penetrate the troposphere usually far outside the continent.

The lidar results for these cases are displayed in Fig. 3. A selection of model forecasts corresponding to these cases is shown in Fig. 4. For the final example in this section, a particularly spectacular intrusion in November 2001, no lidar measurements were available due to ongoing laser problems. Instead, we include the Zugspitze series for the respective period.

\subsection{March-2 April 2001}

The intrusion period 31 March to 2 April 2001 yielded a particularly nice measurement series showing three in part simultaneously subsiding tongues of stratospheric air (S1, S2, $\mathrm{S} 3$ ). One lidar measurement was also made up to $3.2 \mathrm{~km}$ (below a cloud layer) on 2 April at 07:30 CET and shows the extension of intrusion $\mathrm{S} 2$ with a peak mixing ratio of $69.6 \mathrm{ppb}$ (Zugspitze: up to $70 \mathrm{ppb}$ during the preceding hours, see Fig. 5). The lower two intrusions ( $S 1$ and S2) were both observed at the Zugspitze summit (relative humidities between 10 and $20 \%$, peak ozone around 75 ppb in both cases), whereas the third one did not lead to a pronounced signature on the following days (Fig. 5). The Hohenpeißenberg ozone sonde launched on 2 April at 05:35 CET yielded a rather constant ozone mixing ratio around $50 \mathrm{ppb}$ above $4 \mathrm{~km}$, without any sign of S3, but up to $60 \mathrm{ppb}$ below $4 \mathrm{~km}$ indicating the presence of $\mathrm{S} 2$. The absence of $\mathrm{S} 3$ in the sonde profile suggests that this intrusion had already moved out of the observational area, as confirmed by the forecast trajectories.

Although the time series of ozone is clearly structured, the trajectory forecasts look complex and cannot be easily assigned to the observations. Most of the forecasts show a large and rather thick intrusion starting to the south of Greenland and approaching Central Europe on a straight track. This intrusion, assigned to Type 4 because Greenland and Iceland are just missed, can clearly be seen also in the two examples in Fig. 4. It obviously covers a rather extended altitude range as indicated by the ozone measurements during the first hours. The low-lying contributions of this intrusion form layer S1 and continue to overpass Garmisch-Partenkirchen with their eastern edge. S2 and S3 could, in principle, be assigned to higher parts of this intrusion entering the observational area at later times, but this view is too simple (see below).
There is some moderate concentration gap between layer S3 and the tropopause (Munich: $12 \mathrm{~km}$ ). The analysis verifies that no tropopause folding was observed in the case of layer S3. The 12:00-UTC panel in Fig. 4 indicates that the intrusion originated over Labrador (Type 5) and stayed at high altitudes during the entire passage across the Atlantic, before it turned southward and started its final descent. This northsouth section rapidly moved eastward across Central Europe, in agreement with the short observation of S3. Layer S2 cannot be clearly assigned.

To deepen the understanding a twenty-day FLEXPART retroplume analysis was carried out for four times on 1 April (not shown). This analysis clearly assigns $\mathrm{S} 1$ to the direct Type-4 intrusion shown in Fig. 4. S3 can be assigned to the Canadian air stream, but also shows significant pick-up of stratospheric air during the travel across the Atlantic. The ETH potential-vorticity plots for 29 March (matching the pressure plots presented in Fig. 4, but with colour coding in pvu, see Sect. 4.7), indeed, indicate contributions with more than 1.5 pvu west of Ireland.

For S2 a different mechanism was found, which means another increase in complexity. Although a minor fraction of the STT took place over Canada (Type 6) the largest stratospheric fractions (up to $11 \%$ ) was obtained over Eurasia at moderate latitudes, roughly fifteen to twenty days backward in time. This branch resembles the principal path along the subtropical jet stream described in the case studies in the companion paper (Trickl et al., 2009). Because of the persistence of this feature (Sprenger et al., 2003; Koch et al., 2006) we also assume a reasonable reliability of the FLEXPART results for these long backward times.

Figure 6 shows the maximum values of the daily stratospheric fractions within the twenty days of the FLEXPART backward calculation for the four times selected. It is interesting to note that the FLEXPART stratospheric fractions for S1 and S2 on individual days are less than 14\%, in some contrast to the rather strong signature in both the ETH forecast and the Zugspitze data (Fig. 5; see in particular the strong ${ }^{7} \mathrm{Be}$ values exceeding $10 \mathrm{mBqm}^{-3}$ on both 1 April and 2 April). The stratospheric fraction for layer S3 is substantially higher at the beginning. The low fraction for S1 could be due to the limited vertical resolution of the model and, as a consequence, to overestimating the influence of mixing the thin $(0.8 \mathrm{~km})$ air stream with tropospheric air which is indicated by the non-negligible fraction of particles with boundary-layer contact found in the model results. Significant mixing does not look that likely because of the very sharp edges of S1 in both the lidar and the station results (see Fig. 5). 

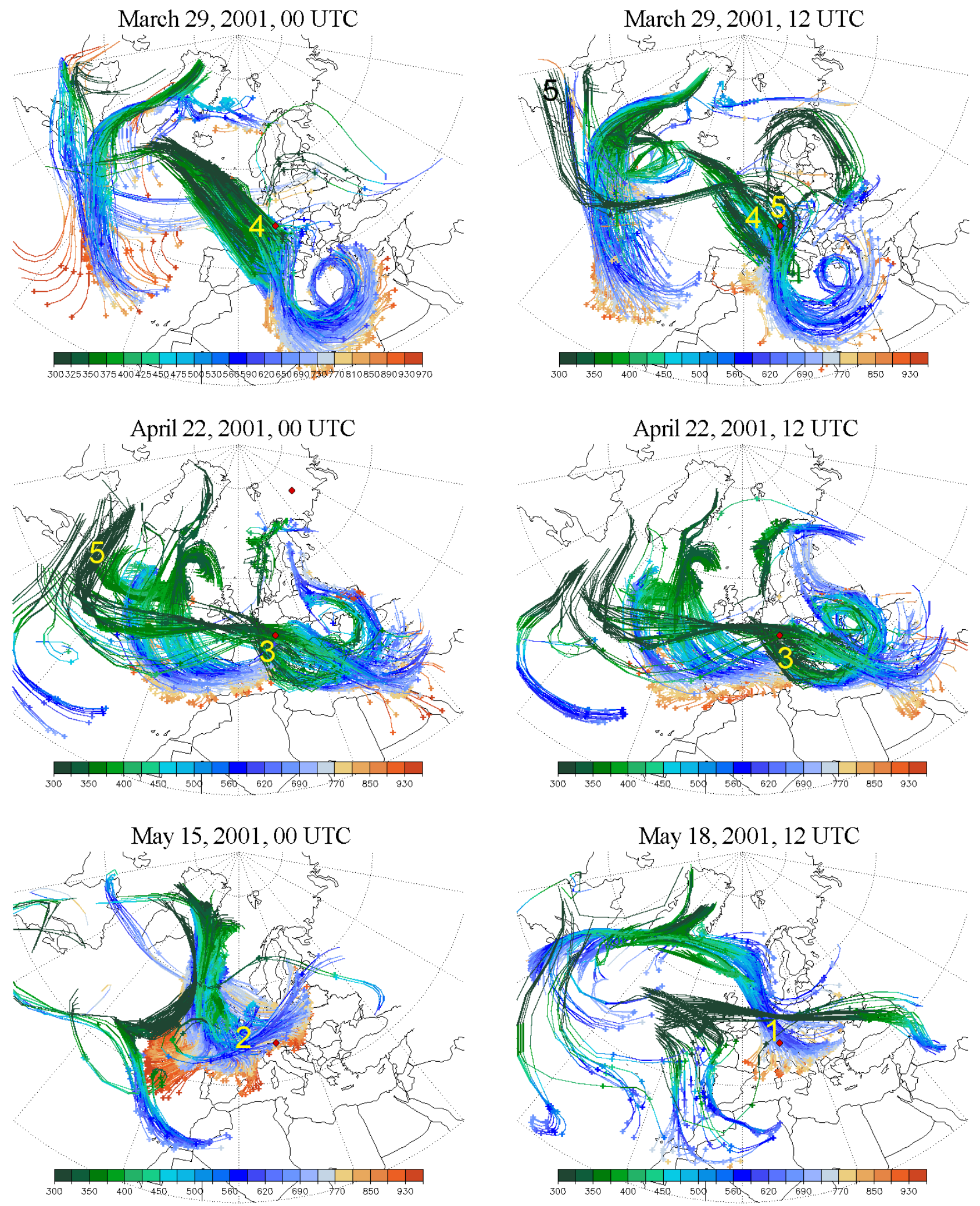

Fig. 4. Four-day trajectory forecasts by ETH Zürich for the cases displayed in Fig. 3; the crosses mark the position every $24 \mathrm{~h}$ after the start times shown at the top of each panel. The pressure level is colour coded in mbar. The Zugspitze summit (marked by a red dot) corresponds to about 700 mbar. The coloured numbers indicate the intrusion type, for the June-2001 case also the intrusion numbers (S2, S4) are given. 


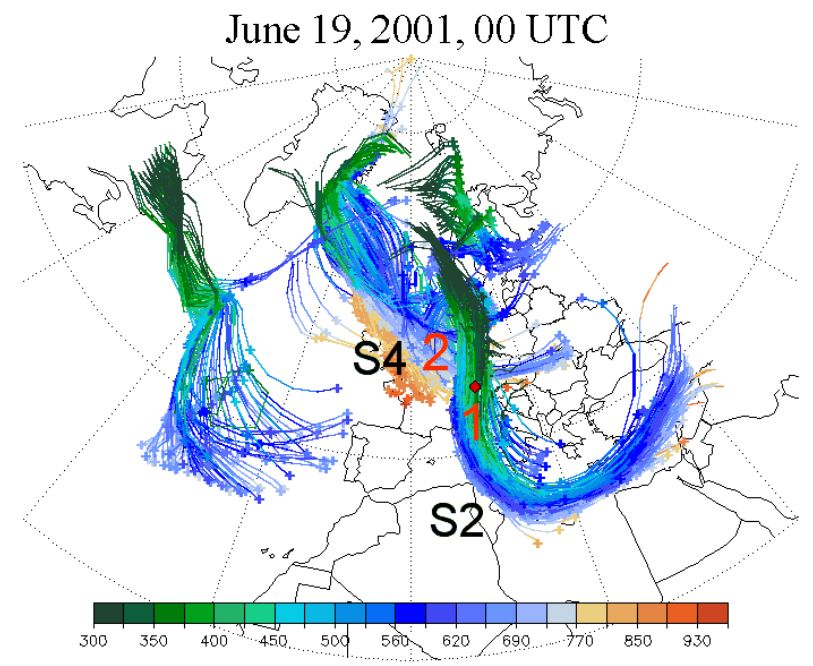

July 18, 2001, 12 UTC

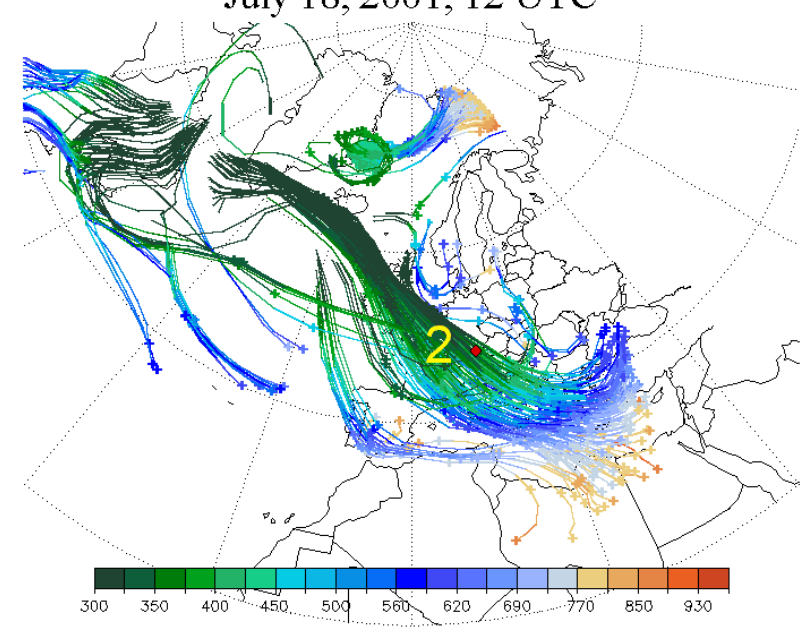

August 8, 2001, 12 UTC

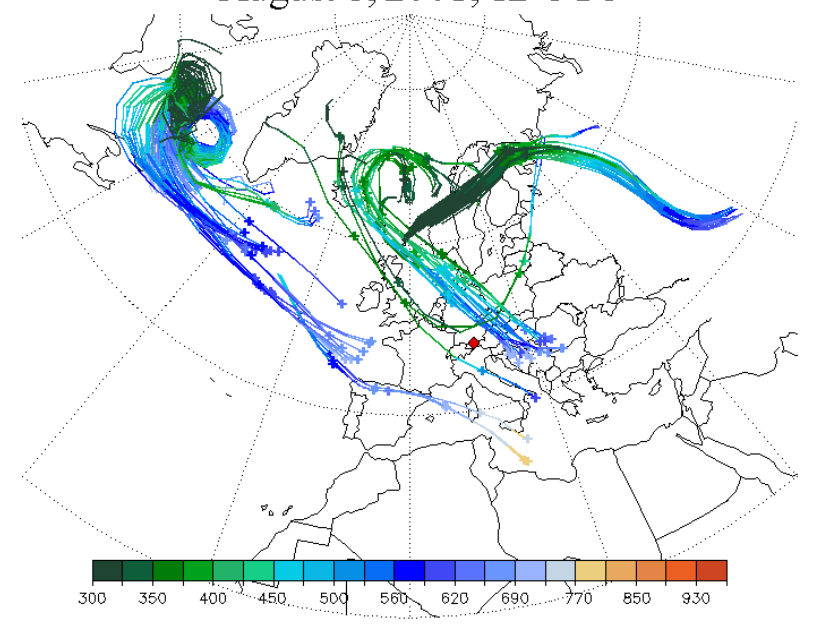

June 20,2001, 12 UTC

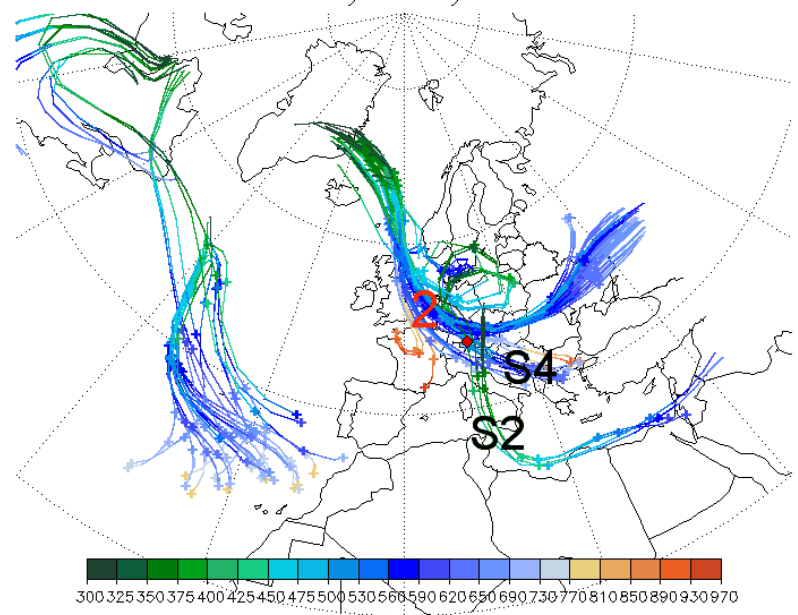

July 20, 2001, 00 UTC

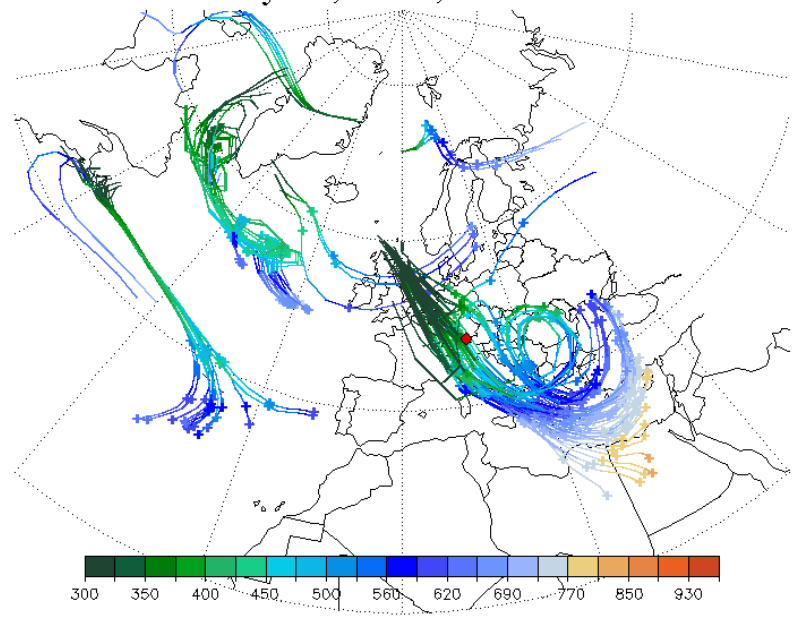

August 9, 2001, 00 UTC

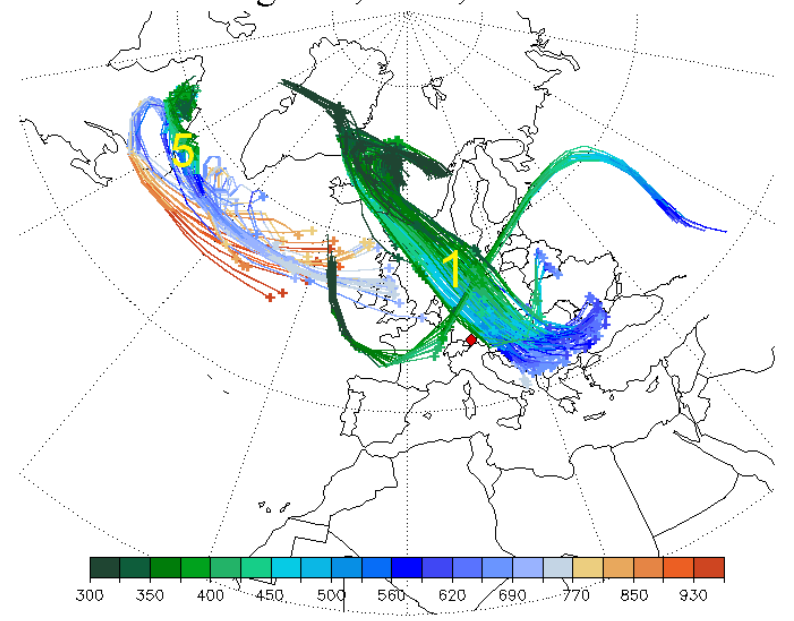

Fig. 4. Continued. 


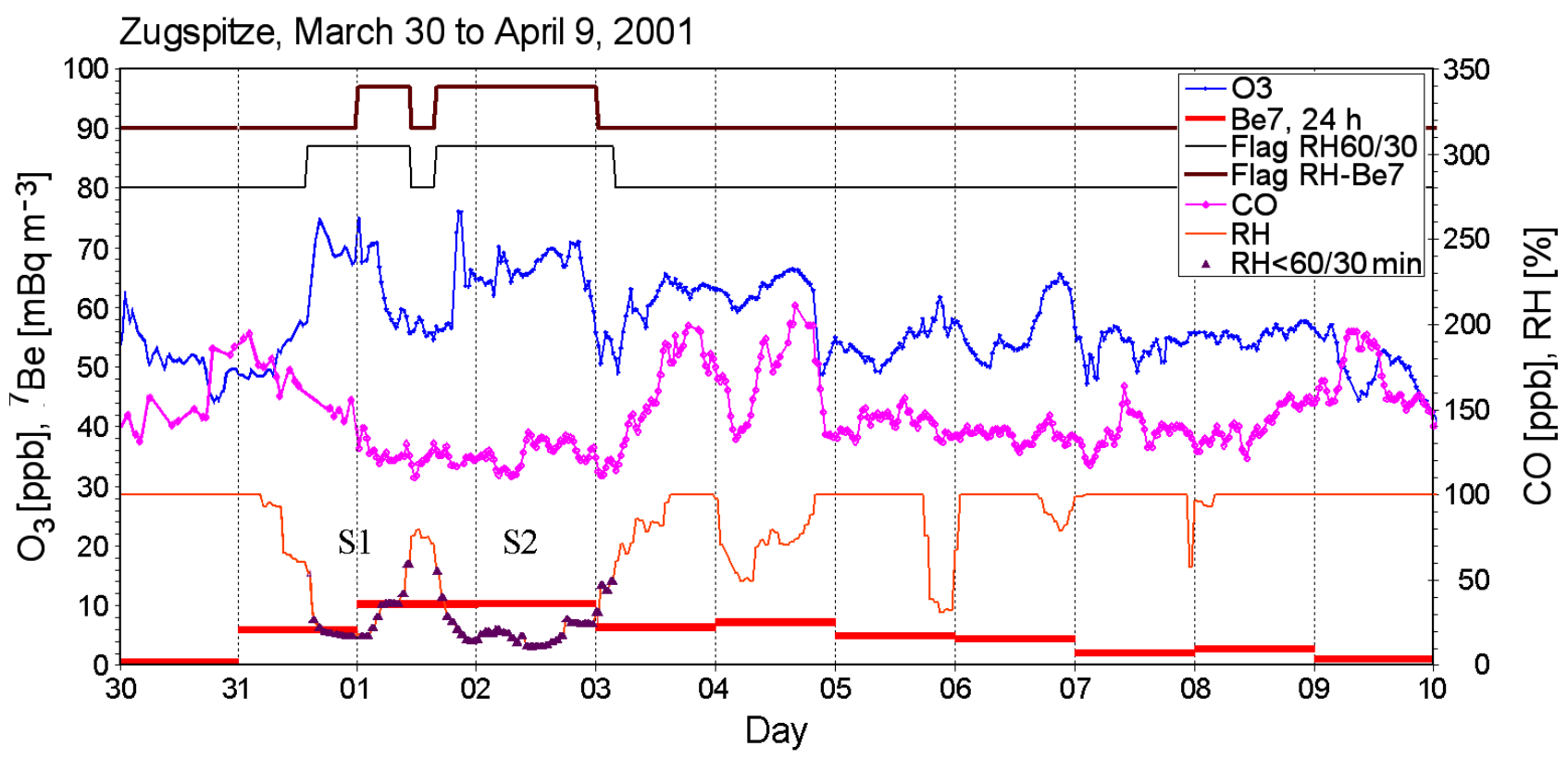

Fig. 5. Zugspitze ozone, carbon monoxide, ${ }^{7} \mathrm{Be}$, and relative humidity (RH) on 30 March to 9 April 2001; the upper two traces indicate the validity on filtering criteria 1 (elevated values in dark red curve) and 2 (elevated values in black curve) described in Sect. 5 . The violet triangles on the RH curve mark the validity range of Criterion 2. The two intrusions (S1 and S2) are defined as in the first panel of Fig. 3. Due to the short coverage of 31 March by the first intrusion (S1) the ${ }^{7}$ Be values do not reach the "classical" threshold condition for stratospheric air of about $8 \mathrm{mBq} \mathrm{m}^{-3}$ (85th) percentile.

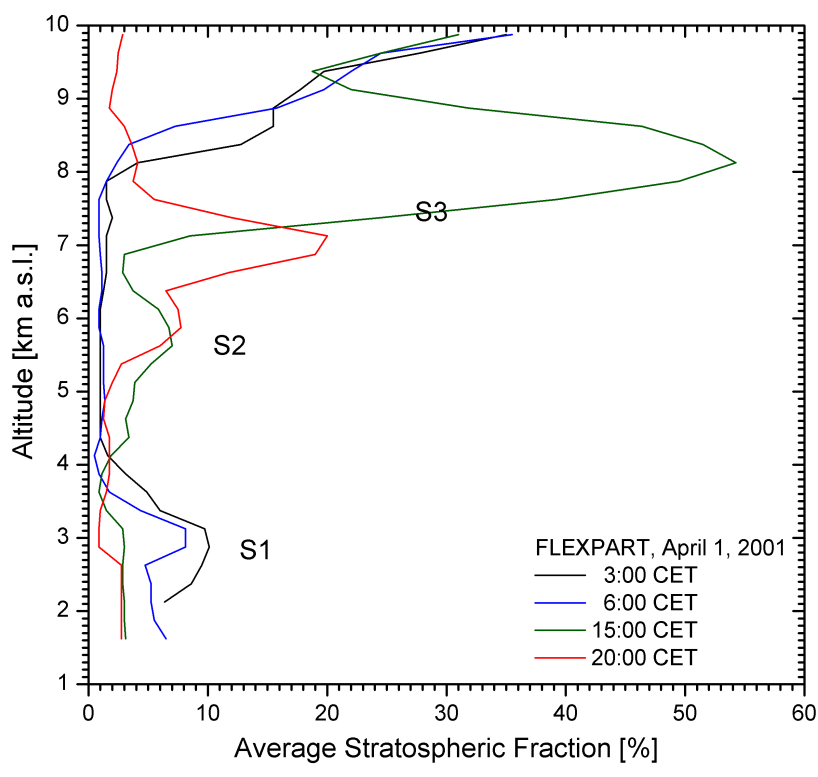

Fig. 6. Maximum values of the daily stratospheric fractions obtained along the FLEXPART retroplumes calculated for four times on 1 April 2001, releasing the numerical particles in vertical intervals of $250 \mathrm{~m}$.

\subsection{April 2001}

This is the first example of a tropopause fold that we can consider to be fully captured with the lidar (S). Again, the outflow from the stratosphere started rather close to our site, over the south-west corner of the North Sea and the UK. The stratospheric streamer quickly moved outside the observational area.

\section{$4.3 \quad 20-23$ May 2001}

Two intrusions (S1 and S2) occurred during this period. Unfortunately, no lidar sounding was possible during the early part of S2 due to low-lying clouds. The Zugspitze data also indicate a pronounced stratospheric influence during the first halfs of both 20 May and 21 May with a rise in ozone from 47 to $62 \mathrm{ppb}$ and 59 to $67 \mathrm{ppb}$, respectively, a relative humidity falling below $20 \%$, and ${ }^{7} \mathrm{Be}$ values of about 6 and $9 \mathrm{mBq} \mathrm{m}^{-3}$, respectively. S2 is seen in the Zugspitze record for just less than $2 \mathrm{~h}$ on 23 May, with a sharp ozone rise to almost $68 \mathrm{ppb}$, but just about $5 \mathrm{mBq} \mathrm{m}^{-3}$ of ${ }^{7} \mathrm{Be}$ due to the very short duration of that event. The Munich radiosonde (launched twice a day $100 \mathrm{~km}$ roughly to the north of IMK-IFU) registered a significant drop in humidity above $1.5 \mathrm{~km}$ a.s.l., reaching $\mathrm{RH}$ values below $10 \%$ in the middle troposphere.

The first intrusion (S1, "classical" Type-2) first proceeded southwards from Greenland and then split into different 

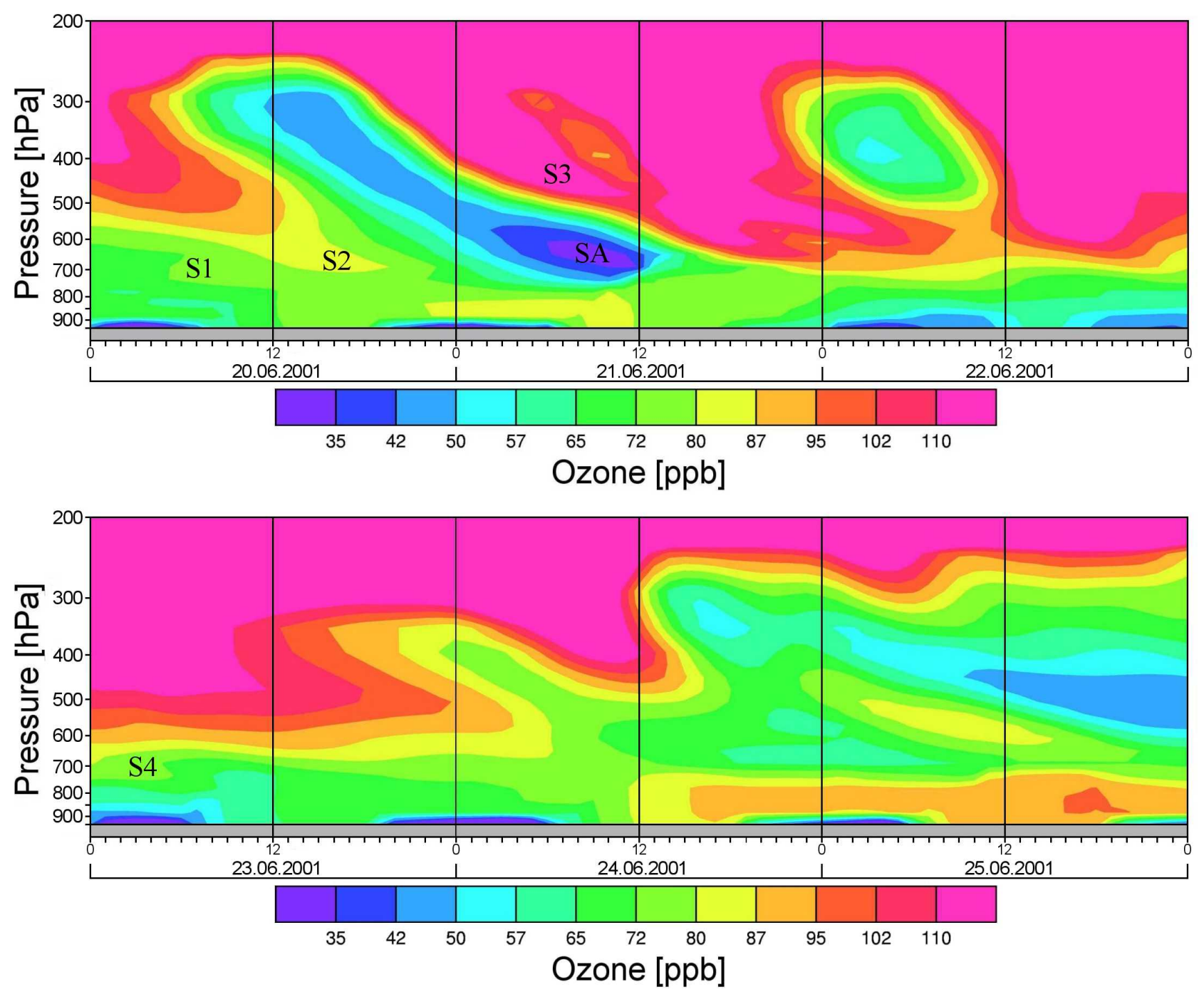

Fig. 7. EURAD simulation for the period 20 June to 25 June 2001; the labels are the same as in the corresponding panels of Fig. 3 . Time: $\mathrm{UTC}=\mathrm{CET}-1 \mathrm{~h}$.

portions travelling at different altitudes, two of them reaching Garmisch-Partenkirchen on 19 and 20 May (see 15 Maypanel in Fig. 4). The second intrusion (S2) was a typical direct Type-1 intrusion with anti-cyclonic advection path originating over Greenland (see 18-May panel in Fig. 4).

Another increase in Zugspitze ozone is seen in the evening of 23 May, but corresponds to air of high relative humidity. Thus, the corresponding layer at the end of the lidar measurements cannot be associated with an extension of the second intrusion.

\section{$4.4 \quad 20-25$ June 2001}

The lidar measurements on the first two days of this period (Zanis et al., 2003) served as a reference for an extensive model intercomparison and validation exercise within the STACCATO project (Roelofs et al., 2003). Recently, the EURAD model was also tested for this complex stratospheric intrusion case (Fig. 7).

Three layers very likely of stratospheric origin (S1-S3) are identified by the lidar and Zugspitze measurements on 20 and 21 June, another one (S4) on 23 June, following a cloudy period over the Alps on 22 June which interrupted the measurements. Intrusions S2 and S3, the latter observed all the way down from the stratosphere, were discussed at length by Zanis et al. (2003). 
Due to the finer spatial resolution the agreement of the EURAD calculation with the data from the lidar sounding at Garmisch-Partenkirchen is (in part substantially) better than that reported for the different models used in the study by Roelofs et al. (2003). The EURAD result shows elevated ozone in all four layers, in particular also S1 which was reproduced (downward shifted) by just one of the model simulations described in the two preceding publications on this case. The interesting downward step in the afternoon of 20 June revealed by the lidar measurements is also visible in Fig. 7. S4 is not fully resolved, but indicated by the step from 800 to 700 mbar on 23 June shortly before 10:00 UTC. However, also two differences between the EURAD results and the lidar measurements exist: In the evening of 24 June a descending moderate-ozone layer (about $50 \mathrm{ppb}$ ) is suggested by the model results at about 450 mbar that is not confirmed by the lidar data before the end of the observational period. Also the low-ozone subtropical layer (SA) starts earlier in the EURAD results than in the measurements, possibly due to a shift in grid cell.

We spent some effort to identify the origin of layer S1 which had not been done previously. The Zugspitze data strongly suggest the presence of stratospheric air: almost $8 \mathrm{mBq} \mathrm{m}^{-3}$ of ${ }^{7} \mathrm{Be}$ on 20 June (intrusion $\mathrm{S} 2$ contributed on the following day!), a strong ozone rise to $69 \mathrm{ppb}$, and $\mathrm{RH} \approx 22 \%$. However, this layer cannot be assigned to any of the ETH forecasts. A twenty-day FLEXPART retroplume calculation now indicates air masses slowly descending from altitudes above $8 \mathrm{~km}$ over the north coast of Canada, i.e., outside the model domains of both the ETH forecast and the forward FLEXPART simulation published by Zanis et al. (2003). The stratospheric fraction rises with backward time (starting with day -9), but stays below $10 \%$, the layer width clearly exceeding that in the measurements. This, again, indicates problems in the analysis of narrow stratospheric layers travelling over that many days.

Intrusion S3 is difficult to distinguish in the forecast plots (and not visible in the two examples shown in Fig. 4) since it, in part, horizontally coincides with intrusion S2. As confirmed by trajectory calculations S3 first leaves Greenland on a cyclonically turning pathway followed by an anti-cyclonic turn and some horizontal spreading during the final approach. It is interesting that, in spite of the long travel, the lidar measurements trace the ozone tongue all the way down from the stratosphere.

Intrusion S4 (23 June; not included in the study by Zanis et al., 2003) is seen in both June panels in Fig. 4 and originated over the area between Greenland and Iceland. The ETH forecasts show the typical strong descent of the air tongue to low altitudes before reaching Europe. What is special is the almost horizontal passage of S4 over Garmisch-Partenkirchen without any residual subsidence. The second forecast indicates that a separate filament was observed, not the main air stream of the intrusion.
The high-ozone layers above $8 \mathrm{~km}$ on 23 and 24 June were examined by trajectory calculations. The results indicate import of air from the Pacific or beyond, potentially loaded with stratospheric air as discussed in the companion paper (Trickl et al., 2009).

\section{$4.5 \quad 21-24$ July 2001}

The four-day sounding series from 21 to 24 July 2001 is another, particularly nice example of the typical ozone time series observed at Garmisch-Partenkirchen after the beginning of high-pressure periods during the warm season (Trickl et al., 2003). In Fig. 2 we just show the results for the first two days of observation. The observations above $2 \mathrm{~km}$ after 21 July are explained in detail in our parallel papers on air-mass advection from beyond North America (Trickl et al., 2009) and from the subtropical Atlantic (Trickl et al., 2010). Here, we briefly discuss the stratospheric air intrusion on 21 and 22 July. This intrusion is (as the 2021 June case) special since also a sudden downward step is observed (in the early afternoon of 21 July). This is ascribed to a splitting of the intrusion into two components, a higher-lying component more to the east and a strongly descending component more to the west. Very interestingly, as the source region shifts towards Europe, first the trajectories by-pass South Germany (panel for 18 July 12:00 UTC), later on (panel for 20 July 00:00 UTC) they, again, overpass our site at high altitude and could result in another contribution in the upper troposphere during early $21 \mathrm{July.} \mathrm{This} \mathrm{cannot}$ be clearly distinguished since the lidar measurements did not start before 13:00 CET (12:00 UTC).

The result extracted from the EURAD run for this case (not shown) nicely reproduces the characteristic features of this intrusion, in particular the downward step in the afternoon of 21 July. However, the calculation yields a slightly lower final altitude of the stratospheric air tongue than the lidar measurements.

\subsection{2-15 August 2001}

Although this it is not fully clear from the last panel of Fig. 3 the "classical" three-layer structure is seen that is reproducibly observed during high-pressure situations (in this paper in particular in the example shown in Sect. 4.5). The reason for this deception is that the subtropical layer (SA) above the intrusion $(\mathrm{S})$ is very short in duration in this case.

This is an example for which the ETH forecast did not fully agree with the observations. The large trajectory bundle in the last panel of Fig. 3 just misses GarmischPartenkirchen, the high-pressure zone obviously having already proceeded to the east at the time of the intrusion (unfortunately, this forecast resulted in a late start of the lidar measurements). However, the Zugspitze data reveal that the edge of the intrusion was even fully caught. A considerable drop in relative humidity was observed on 12 August 


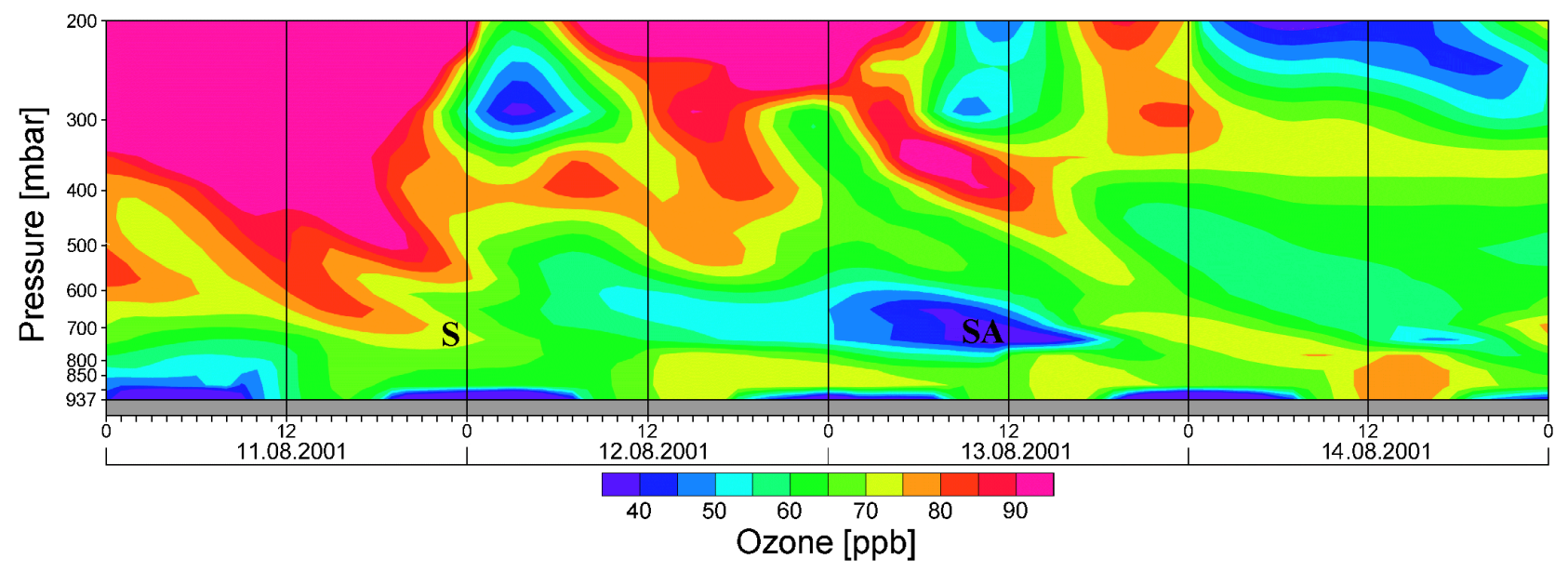

Fig. 8. EURAD simulation for the period 11-12 August 2001; the labels are the same as in the corresponding panel of Fig. 3. Time: $\mathrm{UTC}=\mathrm{CET}-1 \mathrm{~h}$.

between 0:00 CET and 18:00 CET (minimum: 3\%), with the ozone mixing ratio rising by $17 \mathrm{ppb}$ (to $66 \mathrm{ppb}$ ) and a ${ }^{7} \mathrm{Be}$ value as high as $11.5 \mathrm{mBq} \mathrm{m}^{-3}$. With the observational site being located on the west side of the rather straight trajectories we assign Type 1 to this intrusion, although Type 2 would be more adequate for stations further to the east.

During the early part of 13 August the relative humidity, again, dropped, but to values not much below $30 \% .{ }^{7} \mathrm{Be}$ was still above $8 \mathrm{mBq} \mathrm{m}^{-3}$, but there was no pronounced increase in ozone. The most prominent feature in the lidar measurements (LA) during that period is located at about $4 \mathrm{~km}$ and, indeed, does not fully overlap with the summit station. Trajectory calculations revealed long-range advection from at least the upper troposphere above the Northern Pacific. The high ${ }^{7} \mathrm{Be}$ value strongly indicates an origin of this air mass in the stratosphere.

Also the EURAD simulation (Fig. 8) clearly shows the presence of the intrusion (S). As in the measurements it was already located below $3 \mathrm{~km}$ (700 mbar) by the beginning of 12 August. Also the elevated-ozone features in the middle troposphere on 12 August are nicely reproduced. Layer LA on 13 August is missing. Instead, the subtropical layer (SA) is wider. This deviation might be caused be a slight geographical shift in the model results. The high-ozone layer at about 450 mbar starting on 13 August at 19:00 UTC and persisting also on 14 August confirms the corresponding layer in the lidar measurements, but with mixing ratios lower by roughly $50 \mathrm{ppb}$. The mostly stratospheric nature of the ozone increase in this layer (featuring very low EURAD CO) is further discussed in our companion paper (Trickl et al., 2009).

\subsection{4-22 November 2001}

Figure 9 shows one trajectory forecast during one of the most spectacular intrusion cases observed since the beginning of

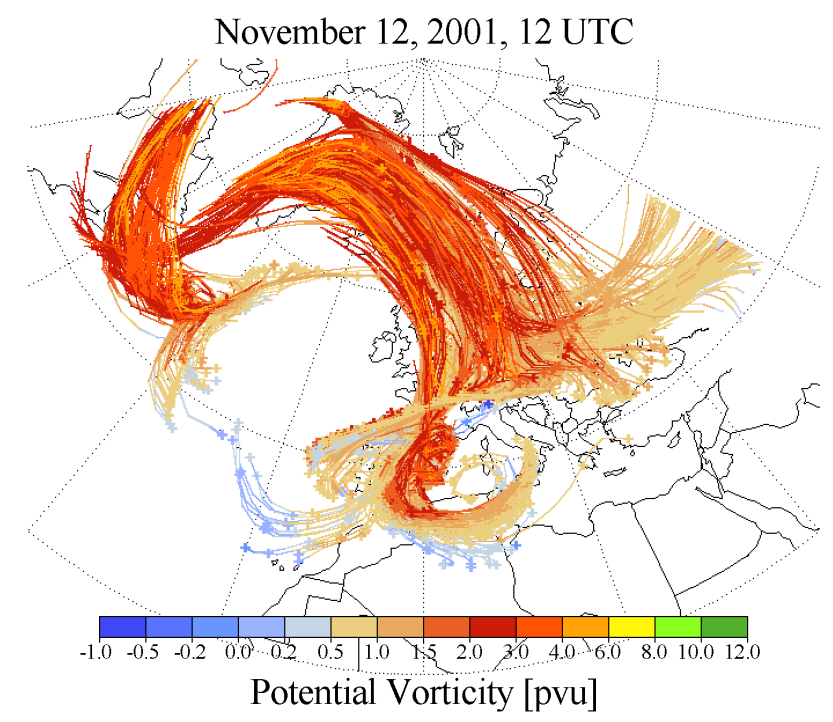

Fig. 9. Four-day trajectory forecast initialized on 12 November 2001, at 12:00 UTC: the intrusion covers most of the European continent. It lasted for six days (Zugspitze summit: 14-19 November) and was followed by the advection of stratospheric air from Canada. The colour indicates potential vorticity here.

these forecasts. The outflow from the stratosphere over Greenland continued over many days and covered most of the European continent. The intrusion was observed at the Zugspitze station from 14 to 22 November 2001 (Fig. 10). The ${ }^{7} \mathrm{Be}$ values were above $8 \mathrm{mBq} \mathrm{m}^{-3}$ from 15 to 19 November, but the ozone mixing ratio stayed between 45 and $65 \mathrm{ppb}$. Due to ongoing problems with the laser system no lidar measurements were possible. This classical Type-1 direct intrusion was immediately followed by the advection of stratospheric air from Canada, which resulted in a total of 


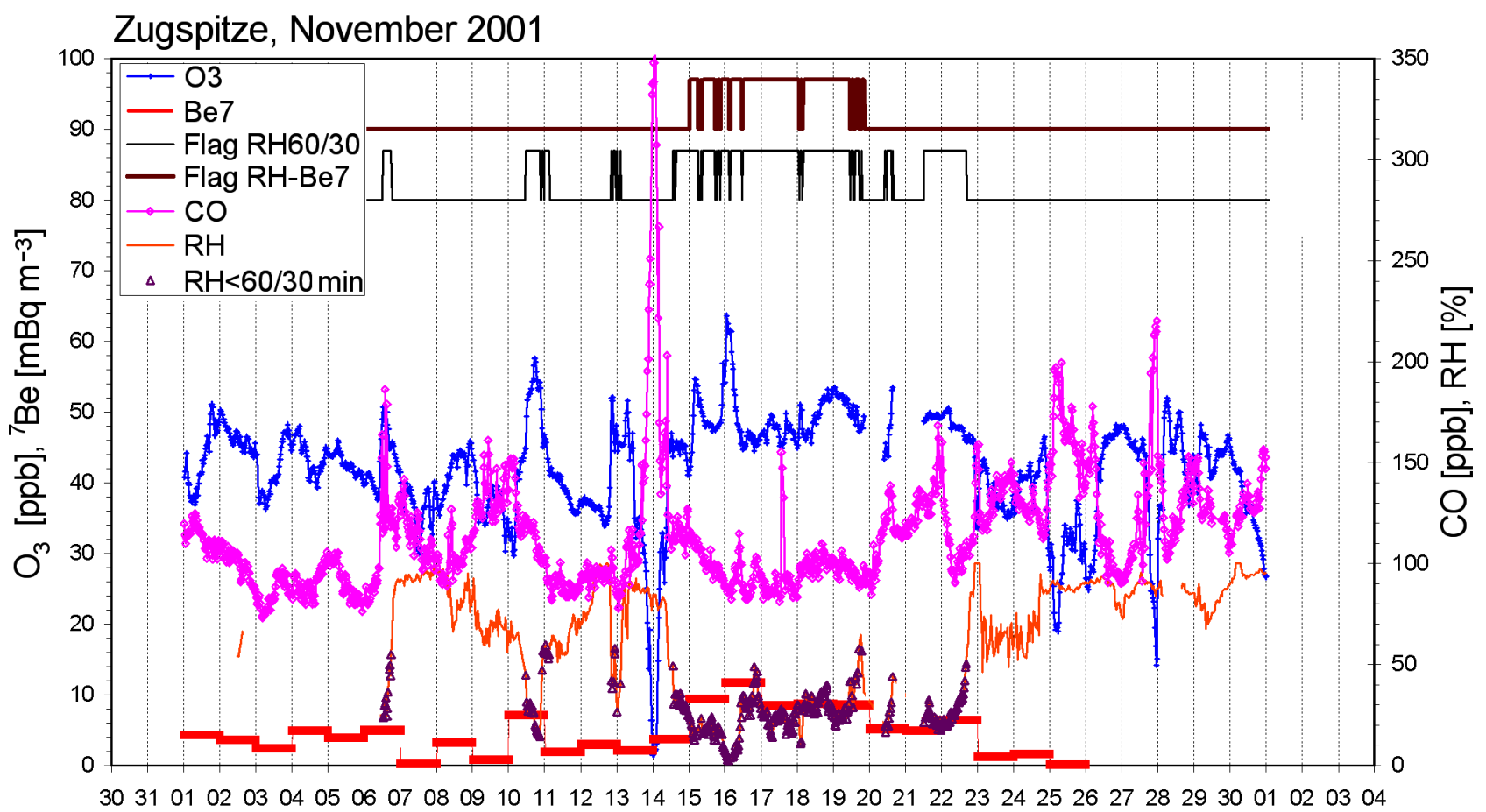

Day

Fig. 10. Zugspitze ozone, carbon monoxide, ${ }^{7} \mathrm{Be}$, and relative humidity (RH) for November 2001; the upper two traces indicate the validity on filtering criteria 1 (elevated values in dark red curve, top trace) and 2 (elevated values in black curve, second trace) described in Sect. 5. The violet triangles on the RH curve mark the validity range of Criterion 2 (Sect. 5). The spectacular CO spike by the end of 13 November corresponds to polluted air advected in the frontal system preceding the intrusion.

nine subsequent intrusion days in the Zugspitze record. An extensive coverage of a month by intrusions is typical of the cold part of the year and demonstrates that much more stratospheric ozone enters the troposphere than previously thought.

During the period 2001 to 2005 a total of more than 10 large intrusions covering major parts of Europe were found. Four of them, including the one in this section, covered about two thirds of the continent and more.

\section{Comparison of ETH model predictions and Zugspitze measurements}

The daily forecasts by ETH Zürich have offered the unique opportunity for examining which observations at the Zugspitze summit are most likely related to stratospheric intrusions and to exclude pure advection from the upper troposphere. In this way, also several filtering criteria used for the discrimination of stratospheric air tongues could be tested for the first time. We compared the forecasts and the Zugspitze data for the period 2001 to 2005 . This effort was rather demanding because of the sometimes enormous intrusion clustering over the North Atlantic and because of the additional trajectory analyses.

\subsection{Definition of the data-filtering criteria}

Three filtering criteria for identifying stratospheric intrusion periods in the observations were examined, all based on the ${ }^{7} \mathrm{Be}$ and $\mathrm{RH}$ measurements. No ozone criterion has been used in recent years since the increases in $\mathrm{O}_{3}$ during intrusion periods are rather different in their appearance, requiring a complex algorithm for the discrimination. There is rarely a clear drop in $\mathrm{CO}$ in these stratospheric air streams (Figs. 5, $10,11)$ which also excludes $\mathrm{CO}$ as a tracer. The behaviour of the ozone and $\mathrm{CO}$ mixing ratios was, however, in most cases inspected on the monthly plots used for the work presented here. The criteria are:

- Criterion 1: The ${ }^{7} \mathrm{Be}$ value corresponds to more than the 85 th percentile with respect to all data in the respective year and $\mathrm{RH}<60 \%$. The ${ }^{7} \mathrm{Be}$ threshold was chosen to match the "classical" threshold for the 24-h specific activity of $8 \mathrm{mBq} \mathrm{m}^{-3}$ (Sladkovic and Munzert, 1990) during the late 1990s. The RH threshold corresponds roughly to the full width at half maximum of many of the humidity troughs caused by the passage of a stratospheric layer. Lower RH thresholds yielded too low fractions of stratospheric ozone. This criterion 


\section{Zugspite, January 2003}

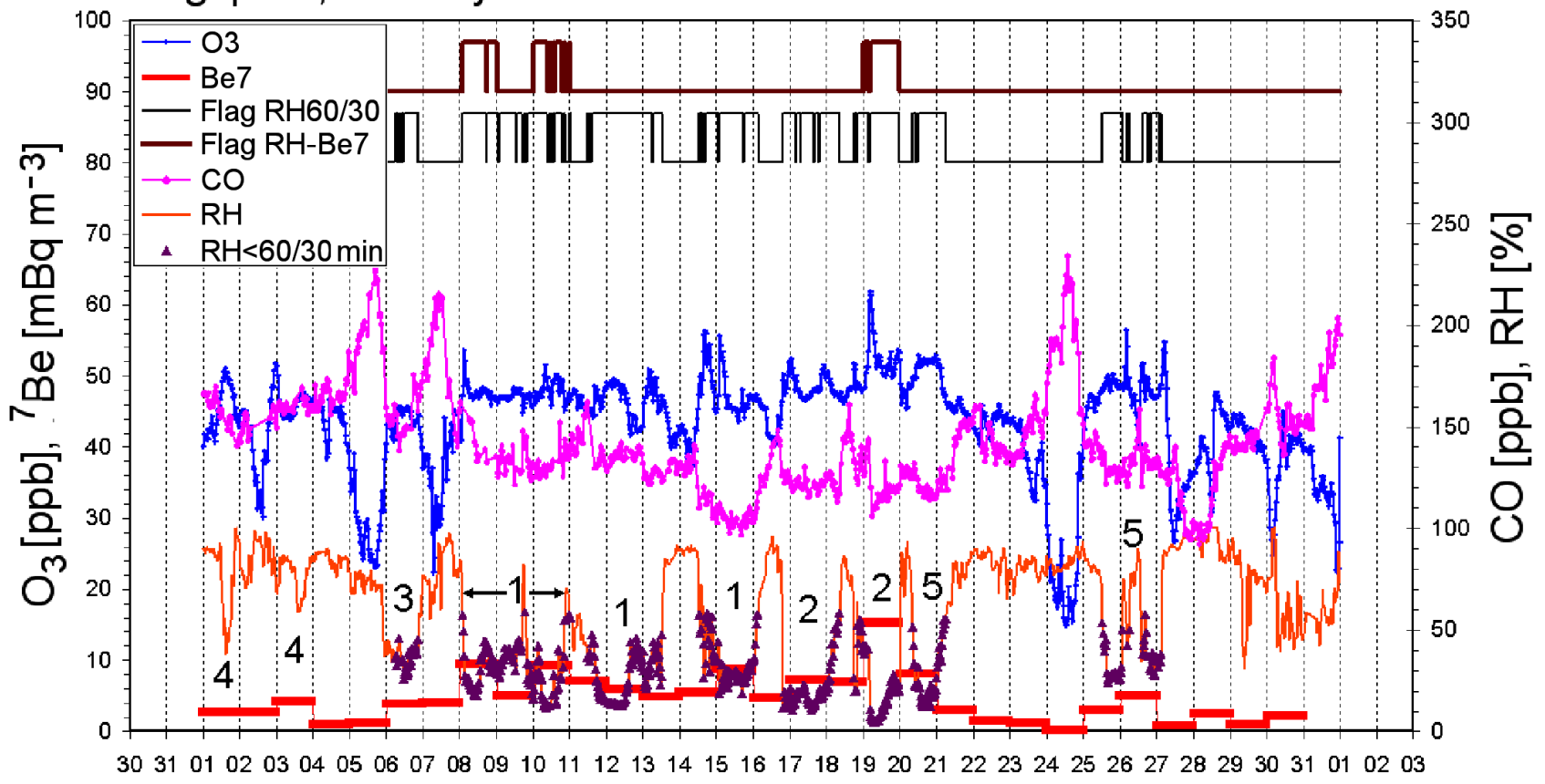

Day

Fig. 11. Zugspitze data for January 2003 (for details see Fig. 5); the numbers next to the RH curve specify the intrusion type obtained from the trajectories.

has been routinely used during the past decade (e.g., Scheel, 2003; ATMOFAST, 2005).

- Criterion 2: $\mathrm{RH}<60 \%$ and $\mathrm{RH}<30 \%$ for at least one of the half-hour averages within $\pm 6 \mathrm{~h}$. The second threshold is added to guarantee really dry conditions as expected for stratospheric air. This threshold is higher than those used by Beekmann et al. (1997), but this is adequate due to the rather low tropospheric altitude of the station.

- Criterion 3: Same as Criterion 1, but with $5.5 \mathrm{mBq} \mathrm{m}^{-3}$ as the threshold for ${ }^{7} \mathrm{Be}$. The application of this lower threshold was examined because Criterion 2 yielded so many more STT cases. The value was chosen from an inspection of many of the monthly plots for the Zugspitze data.

\subsection{Results of the comparison}

The forecasts by ETH Zürich yielded substantially more intrusion cases than we would have registered with our formerly used forecasting or data filtering approaches which yielded only very deep intrusions that rarely miss the Zugspitze summit. An important consequence is that there are also quite a few stratospheric air tongues during all seasons not fully reaching $3000 \mathrm{~m}$. These "medium intrusions"
(Sprenger et al., 2003) may even overpass the Alps when there is ongoing rain or snowfall in the lower elevations prohibiting optical remote sensing.

Table 2 lists the number of cases for these types and of the tropospheric cases, as identified by the model calculations, identified during the period 2001-2005. The number of intrusion cases per year (which may last for several days) is 82.2, which substantially exceeds any estimate in the past. Also the average number of intrusion days per year, 154, is very high and demonstrates the significance of STT for the annual ozone budget. The fraction of the predicted (or verified) intrusions reaching the Zugspitze summit per year, identified by at least one of the three filtering criteria, is $77.9 \%$. It was also found that about $95 \%$ of the forecasted intrusion cases led to a clear signature in either ${ }^{7} \mathrm{Be}$ or $\mathrm{RH}$, or both, though not always fulfilling the criteria. The difference with respect to the fully accepted cases is mostly caused by overpasses missing the summit. In a few predicted cases measurements were missing, in others significant mixing with tropospheric air due to a travel time exceeding four days is hypothesized. Just in 16 cases during the five years of analysis no stratospheric assignment of observations fulfilling one of the criteria could be made (bottom line of Table 2). In all but one of these cases a rise in ozone by at least a few ppb simultaneous to a drop of $\mathrm{RH}$ to below $50 \%$ was seen. These episodes were mostly rather short and, therefore, perhaps not 
Table 2. Overview of the number of cases suggested by the LAGRANTO and HYSPLIT model calculations for the different intrusion types and for advection within the troposphere within $315 \mathrm{~h}$.

\begin{tabular}{ccccccc}
\hline Type & 2001 & 2002 & 2003 & 2004 & 2005 & Sum \\
\hline 1 & 17 & 22 & 23 & 25 & 18 & 103 \\
2 & 22 & 16 & 22 & 16 & 22 & 98 \\
3 & 8 & 8 & 6 & 10 & 7 & 39 \\
4 & 11 & 1 & 6 & 1 & 2 & 21 \\
5 & 21 & 24 & 12 & 18 & 12 & 87 \\
6 & 7 & 4 & 7 & 12 & 21 & 51 \\
7 & 1 & 2 & 1 & 1 & 0 & 5 \\
8 & 0 & 0 & 2 & 1 & 5 & 8 \\
Sum & 87 & 75 & 79 & 84 & 87 & 412 \\
"Tropospheric" & 3 & 1 & 3 & 4 & 5 & 16 \\
\hline
\end{tabular}

captured by the backward trajectory analysis. The backward trajectories did not reach sufficient height or, in a few cases, even stayed in the middle and lower troposphere within the preceding $315 \mathrm{~h}$. Finally, it is important to note that the true number of intrusion cases may be, still, higher since our model analysis does not include overpasses that originate outside the domain of the ETH model. However, this does not make any difference in the validation of the filtering criteria since here only the cases leading to an observation matter.

The highest counts were found for Types 1,2, 5 and 6, but also Types 3 and 4 are relevant. Types 7 and 8 occur just once or twice per year on average. It is important to know that these pathways exists, but this rate is too low for any significant statistical analysis. In the following, we focus on Cases 1 to 6.

Two examples for the Zugspitze series were already given in Sect. 4 (Figs. 5 and 10). In the example in Fig. 5 the most typical problem with ${ }^{7} \mathrm{Be}$ as a tracer is seen on 31 March 2001. Due to just a partial coverage of that day by intrusion 1 the 24 -h average of ${ }^{7} \mathrm{Be}$ is below the threshold for Criterion 1. It is advisable to improve the time resolution of the ${ }^{7} \mathrm{Be}$ measurements to half a day or even less.

In order to highlight how many different intrusions can occur during a single month we show in Fig. 11 another example typical of the cold season (January 2003). The types of the different intrusions are marked in the figure next to the RH curve. The first two intrusions passed above the summit and, therefore, yield less pronounced signatures. In general, the Types 5 and 6 make a significant contribution during the dark period of the year.

This example (among many others, see also Sect. 4.7) demonstrates that the stratospheric influence in the lower free troposphere during this part of the year is considerable. The time periods for which the "classical" ${ }^{7} \mathrm{Be} / \mathrm{RH}$ criterion (Criterion 1) and the RH criterion (Criterion 2) are fulfilled are marked in the upper two traces. Criterion 2 (see also violet

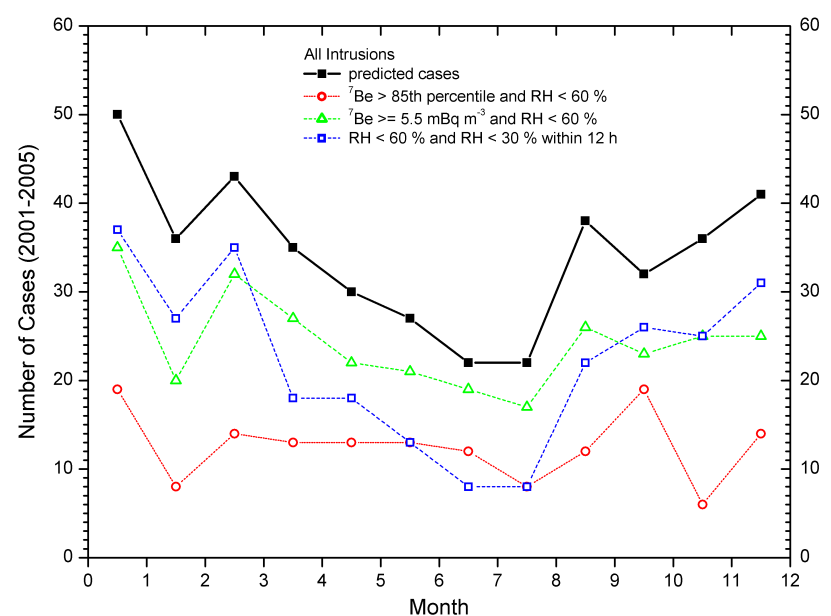

Fig. 12. Total number of intrusion cases predicted or verified by trajectories and total number of cases verified by the data filtering (Criteria 1-3) obtained for 2001 to 2005; please, note that a single intrusion case may extend over several days and may not fulfil the individual filtering criteria during the entire period.

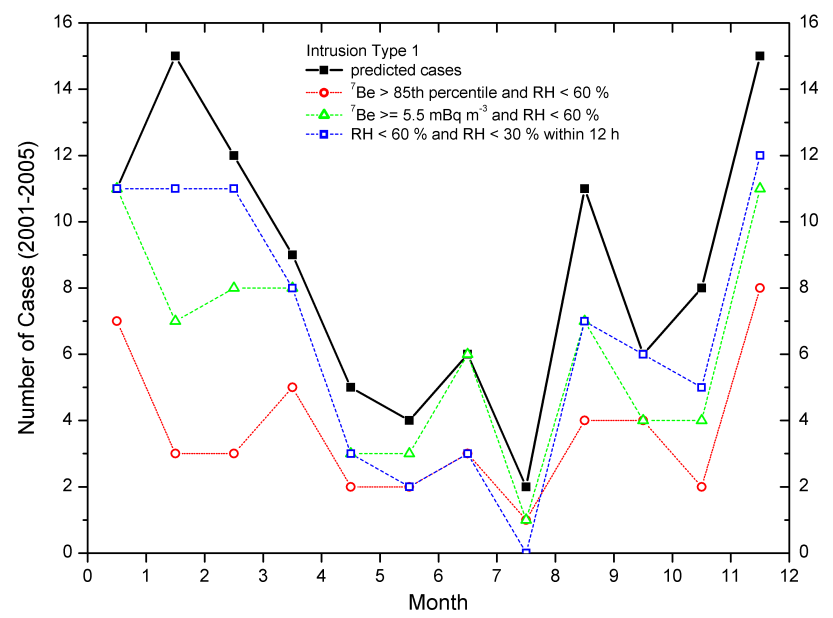

Fig. 13. Same as Fig. 12, but for intrusion type 1 only.

triangles on the RH curve) is substantially more efficient in identifying intrusion periods than Criterion 1. As mentioned above the drop in carbon monoxide during intrusions is mostly not very pronounced, one exception in Fig. 11 being 15 January 2003.

Figures 12 to 16 show the seasonal cycles (2001-2005) derived for the intrusions predicted or verified by trajectories for the four most important intrusion types. As expected, the Types 1, 2 and 5 yield the strongest contributions. For most intrusion types (also Types 3 and 4, not shown) the winter maximum and summer minimum from previous studies is confirmed. However, quite interestingly, for Type 2 we obtain a late-spring maximum. This maximum obviously causes the asymmetry in the seasonal distribution for 


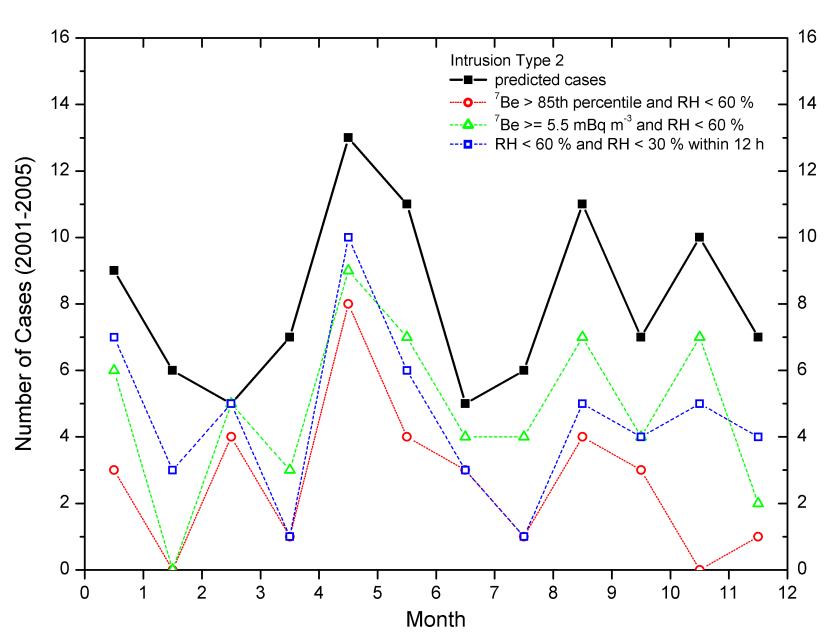

Fig. 14. Same as Fig. 12, but for intrusion type 2 only.

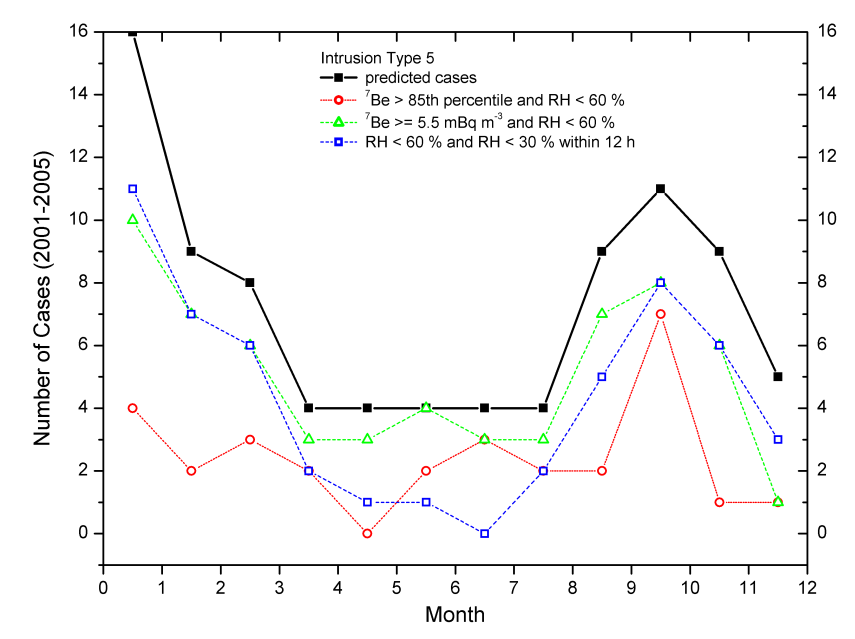

Fig. 15. Same as Fig. 12, but for intrusion type 5 only.

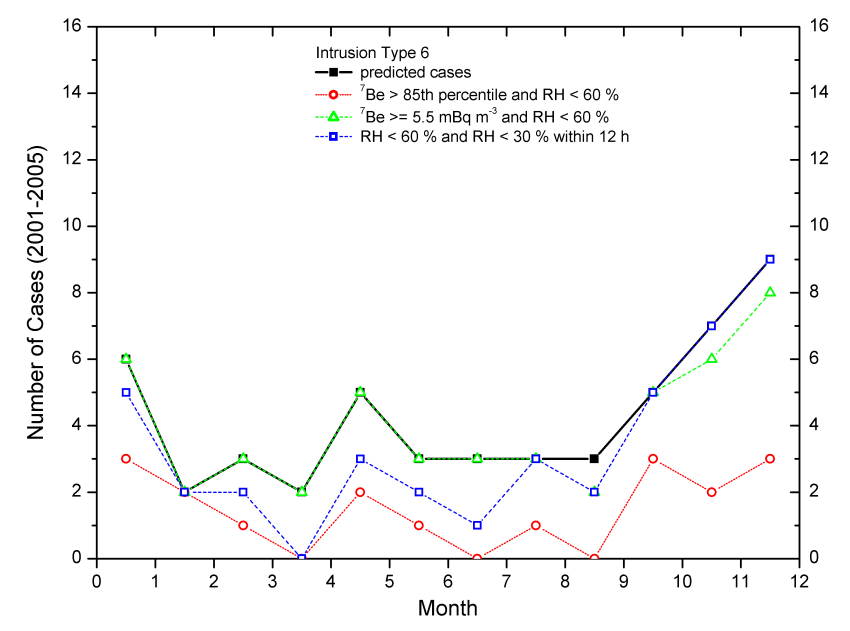

Fig. 16. Same as Fig. 12, but for intrusion type 6 only.

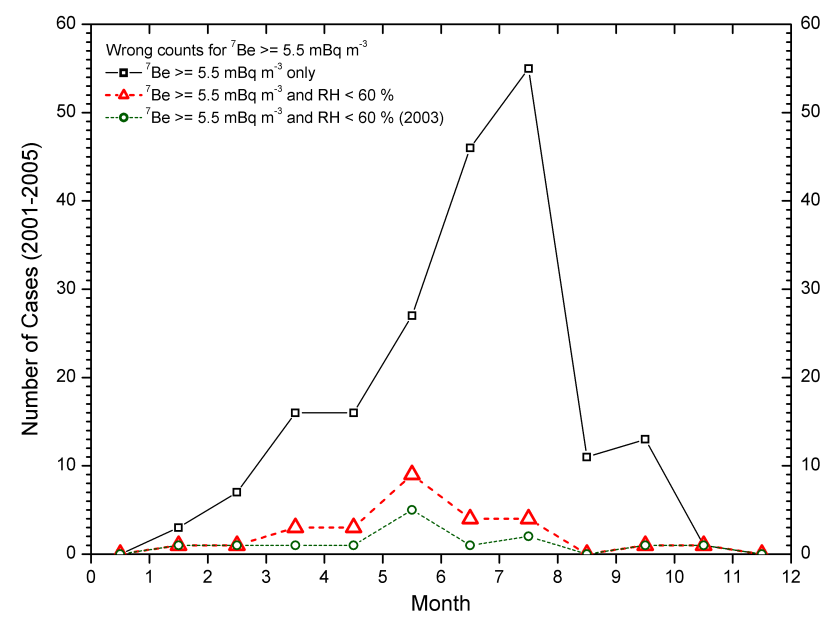

Fig. 17. Seasonal cycle of the cases not related to stratospheric air when using $5.5 \mathrm{mBq} \mathrm{m}^{-3}$ as the ${ }^{7} \mathrm{Be}$ threshold (number of days on which a wrong identification was obtained); the additional use of $\mathrm{RH}<60 \%$ (Criterion 3) is important to reduce the wrong counts.

Fig. 12. This asymmetry is also visible on the FLEXPART result shown in Fig. 1.

Criterion 1 consistently yields just a moderate number of intrusion cases. This is, to a major part, due to accumulating ${ }^{7} \mathrm{Be}$ over $24 \mathrm{~h}$ which may result in an omission of short intrusions or of cases that occur around midnight. However, this criterion is robust and suitable for trend studies. The seasonal cycle for Criterion 1 in Fig. 12 is not very pronounced. The corresponding seasonal cycle for ozone should exhibit a stronger modulation.

Criterion 3, based on a lower ${ }^{7} \mathrm{Be}$ threshold, yields many more cases, close to the number of cases for Criterion 2. With the exception of intrusion Type 2 it works particularly well around the middle of the year. The cases for Criteria 2 and 3 overlap to a major extent, but there are also mismatches. To our great surprise the very simple Criterion 2 almost perfectly corresponds to stratospheric intrusions. During the warm season some cases are missed that are identified by Criterion 3. This could be due to a slightly higher passage with less complete overlap with the summit station or enhanced mixing with tropospheric air resulting in an exceedance of the $30-\%$ threshold.

Criterion 3 was thoroughly tested for the period 20012005. Outside the verified intrusion periods there were just 39 days per year on which $5.5 \mathrm{mBq} \mathrm{m}^{-3}$ were reached or exceeded. The seasonal distribution is shown in Fig. 17. Most of these exceptions, which may sometimes cover an extended period of time with even rather high ${ }^{7} \mathrm{Be}$ values, occur during the warm season. If $\mathrm{RH}<60 \%$ is added the number of erroneously counted days is reduced to just 5.4 per year. However, in all but two cases the period with $\mathrm{RH}<60 \%$ lasted for not more than just a few hours, which implies a very low 
significance of these events. The bad cases are governed by the results for the exceptionally hot year 2003.

Very-low-humidity cases are relatively rare. They are, in principle, expected to be more frequent for short advection paths due to the reduced time for mixing, but also air from remote intrusion events may be considerably dry presumably if the layer is sufficiently thick to avoid a significant admixture of tropospheric air. Normally, a tropospheric travel time of about three days seems to be short enough for avoiding a significant loss of the stratospheric nature of the air.

Figure 18 gives a summary of the fractions of the cases for the statistically relevant intrusion types fulfilling different RH conditions (Type 4 being at the edge of being statistically acceptable here). The highest fractions with $\mathrm{RH}<10 \%$ ( $43.1 \%$ and $36.5 \%$, respectively) were obtained for Types 1 and 6 . The explanation for Type 1 is the mostly rather rapid travel of these "classical" intrusions from Greenland to the Alps within two to three days. In the case of Type 6 the travel time is mostly rather long. Thus, these layers must be sufficiently thick in order to avoid significant mixing with tropospheric air. This conclusion is also hardened by the fact that intrusion type 6 also comprises the lowest fraction of cases with $\mathrm{RH} \geq 40 \%$. The mixing with tropospheric air is further impeded in an aged intrusion layer since it is likely that the layer adopts the velocity of the surrounding air masses during the long travel, resulting in reduced turbulent mixing. We plan more detailed investigations of these layers by simultaneous lidar measurements of ozone and water vapour.

\section{Discussion and conclusions}

The intrusion forecasts have been invaluable for identifying periods during which lidar measurements of STT events were made. The period between February and August 2001 has been particularly successful in this regard and yielded, together with our earlier work (e.g., Eisele et al., 1999; Stohl and Trickl, 1999; Zanis et al., 2003; Roelofs et al., 2003; Trickl et al., 2003) a large variety of different cases with strongly differing complexity. The sometimes enormous number of simultaneously occurring intrusions over the North Atlantic, which may have a large impact on the STT budget, calls for a more detailed meteorological analysis, also in view of potentially changing atmospheric dynamics during the past decades (see remarks on trend studies further below). Still, as pointed out by Eisele et al. (1999), it is very likely in complex situations that at least one of several almost simultaneously observed intrusions descends down to $3000 \mathrm{~m}$ and can be observed at the Zugspitze summit. This probability is lower in summer. The individual intrusions strongly descend during the observational period (Sects. 4.4 and 4.5) or they intersect our area without much change in vertical position, all depending on the distance of the source region to the Alps. Quite frequently, layers of stratospheric air may overpass our area at about $3 \mathrm{~km}$ a.s.l. for several days

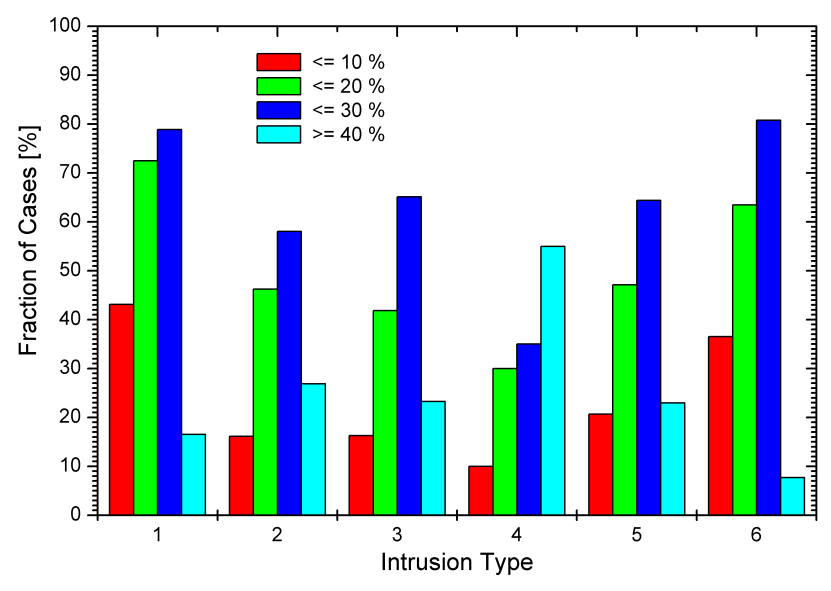

Fig. 18. Fractions of intrusions for six of the eight intrusion types identified in this paper fulfilling different $\mathrm{RH}$ conditions (minimum RH value).

(e.g., Trickl et al., 2003). In these cases they are observed at the Alpine summit stations during an extended period of time. The descending intrusions may occasionally exhibit downward steps (e.g., examples in Sects. 4.4 and 4.5). In Case 5 (Sect. 4.5) this was explained by a splitting of an intrusion into two components. Most importantly, first observations of the initial phase of tropopause folding were made with our ozone lidar.

Intrusion case 4 (Sect. 4.4) has been used for a variety of model validation exercises within the STACCATO (Zanis et al., 2003; Roelofs et al., 2003) and ATMOFAST (this work; Trickl et al., 2009) projects. From the EURAD simulation discussed in this paper we derive a strong indication that a sufficiently high spatial resolution, here $125 \mathrm{~km}$ horizontally and 10 to 40 mbar vertically within the troposphere, is needed to obtain results resembling the measurements. An even higher resolution is desirable for catching also the details in the lower troposphere. Episodic studies with the EURAD model (ATMOFAST, 2005; Ebel et al., 2008) with increased horizontal and vertical resolution confirmed that especially a higher vertical resolution in the tropopause region enhances the ability of the model to reproduce of the dynamics and composition of the upper troposphere/lower stratosphere in more detail.

The forecasts are also an important tool for testing the identification criteria for stratospheric air in the Zugspitze data. It was found that all three data-selection criteria examined work very reliably although there are differences in the individual cases identified. These differences are due to differences in mixing with tropospheric air, due to partial overlap of the stratospheric layer with the summit station (both resulting in a wide range of humidity values), or due to the bad temporal resolution of the ${ }^{7} \mathrm{Be}$ measurements. A few discrepancies might be due to using forecast instead of re-analysis data. However, repeating this excercise with 
improved model calculations is out of the scope of this work. We finally note that overpasses of stratospheric air from outside the domain of the forecast model at high altitude (e.g., Bithell et al., 2000; Trickl et al., 2009) are excluded from the analysis.

The significant coverage of the dark part of the year by stratospheric events, with low humidity frequently extending over many days, suggests that the approach by Elbern et al. (1997) based on eleven-day statistics is not always adequate. The use of ozone as an additional tracer or STT events is also rather restrictive. Their analysis yielded a low number of significant intrusions of 19.5 per year, in considerable contrast to the numbers in Table 2. Our first criterion already yields 29.4 cases per year, but the coverage of the events is, still, moderate in comparison with the predictions. Nevertheless, the percentiles chosen are related to full-year statistics and, thus, the results are less influenced by short-term variations than those by Elbern et al. (1997). A one-year period is sufficiently short in comparison with known periodicities in surface ${ }^{7} \mathrm{Be}$ (Reiter et al., 1983; Koch and Mann, 1996; Gerasopoulos et al., 2003) in order to account for their influence.

Despite the high reliability of the data-filtering criteria examined they do not allow one to distinguish between direct (those with closer-by source regions, in particular Types 1 to 3 ) and indirect intrusions. Even high beryllium values are not fully indicative of short advection paths. The specific activity reaches or exceeds $8 \mathrm{mBq} \mathrm{m}^{-3}$ in about ten Type- 5 and Type-6 intrusions per year. Also high peak ozone values are not necessarily positively correlated with high ${ }^{7} \mathrm{Be}$.

From the results in Fig. 1, showing similar seasonal cycles, we tentatively conclude that the filter criteria reviewed here could be also valid for the other summit stations in Central Europe. However, this must be carefully verified for each individual station.

The considerable number of intrusions observed at the Zugspitze summit, with a strong monthly coverage in late autumn and winter (Figs. 10 and 11) contradicts the frequently read statement that STT has a minor influence on the tropospheric ozone budget. By contrast, Roelofs and Lelieveld (1997) concluded from model calculations that as much as $40 \%$ of the tropospheric ozone originates in the stratosphere. This remarkable fraction was recently approximately confirmed for $3000 \mathrm{~m}$ from the detailed filtering of the Zugspitze data between 1978 and 2004 (ATMOFAST, 2009). This filtering, based on experimental material alone, also confirms a pronounced positive trend in the stratospheric influence already found for the 1990s (Scheel and Kanter, 2002; Scheel, 2003) for the entire period. The Zugpitze ${ }^{7}$ Be series, started in 1970 , shows a positive trend in the specific activity of that isotope since the mid-seventies (Scheel and Kanter, 2002). In the 1990s the positive ozone trend caused by the increase in the stratospheric contribution masked a decrease expected from a reduction in precursor emissions in Europe. In fact, for the nearby lower
Wank station (1780 m a.s.l.), which is substantially less exposed to stratospheric intrusions (Elbern et al., 1997), no significant trend exists during that period. The positive trend in the Zugspitze ozone exceeds that at other, lowlying stations with long data records reviewed by Oltmans et al. (2006), with one strange exception: Mace Head (Simmonds et al., 2004).

The seasonal cycles shown in Figs. 12 to 16 mostly show a winter maximum and a summer minimum. The overall seasonal cycle (Fig. 12) is less pronounced for Criterion 1 than for forecasts and the other two filtering criteria, in agreement with the findings by Reiter et al. (1983) for intrusions with high beryllium values. The asymmetry found for the predicted cases and Criteria 2 and 3 agrees well with the revised FLEXPART model calculation for the Zugspitze summit (Fig. 1). As discussed in Sect. 4.2 this asymmetry is caused by the spring maximum obtained for the Type- 2 intrusions (Fig. 14). This asymmetry also exists in the simulation for Jungfraujoch (southwest of Zugspitze), but not in that for Sonnblick (east of Zugspitze). The cyclonically advected Type-2 intrusions are more relevant for Western Europe. In fact, a maximum of STT between May and July was found for Southern France (Van Haver et al., 1996). However, this view is too simple since Van Haver et al. derived almost the same seasonal cycle also for the troposphere above Uccle (Belgium) that is quite frequently overpassed by the Type-1 intrusions reaching Garmisch-Partenkirchen.

There are several possibilities for improving the performance of the data filtering. The best choice is expected to be a "or" combination of Criteria 2 and 3. From this procedure a coverage of most cases is expected. The analysis for 2001 to 2005 shows an enhancement of the coverage from $64.4 \%$ (Criterion 2) or $70.2 \%$ (Criterion 3) to $77.9 \%$ when using all criteria simultaneously. Of course, the $5.5-\mathrm{mBq} \mathrm{m}^{-3}$ threshold, chosen here as a constant value for simplicity, must be converted to the corresponding percentile as done earlier for the $8-\mathrm{mBq} \mathrm{m}^{-3}$ threshold, yielding the 85 th percentile of a given year. Another possibility could be weighting the ${ }^{7} \mathrm{Be}$ integrated specific activity according to the length of an intrusion. The length could be obtained from applying Criterion 2. However, this approach can be rather difficult due to temporary (short) exceedances of $\mathrm{RH}=60 \%$, data gaps and in the case of intrusions taking place on two subsequent days. It is obvious that better-resolved ${ }^{7} \mathrm{Be}$ data are desirable, e.g., 6-h instead of 24-h averages.

For a complete quantification of STT also the mixing with tropospheric air must be considered. Shapiro et al. (1980) showed that the admixture of tropospheric air already starts in the tropopause region. There is clear observational evidence of an admixture of polluted air to intrusions in the free troposphere (e.g., Parrish et al., 2000; Brioude al., 2007). In many cases the water-vapour content of a stratospheric intrusion should be a good indicator of the amount of mixing. It is reasonable to assume that thick layers of stratospheric origin are drier than thin ones because mixing starts at the 
edges of the layer. One example of a layer several kilometres wide and exhibiting relative humidities of 1.0 to $2.4 \%$ (mixing ratios 79 to $116 \mathrm{ppm}$ ) was recently given by Vogelmann and Trickl (2008), obtained from a measurement with the new water-vapour lidar operated by IMK-IFU about $300 \mathrm{~m}$ below the Zugspitze summit. On the other hand, in the same publication an intrusion as thin as a few hundred metres and featuring just $1 \%$ minimum $\mathrm{RH}$ is shown in the lower troposphere, exactly confirmed by the Munich radiosonde launched $100 \mathrm{~km}$ to the north.

In the Zugspitze data the cases with $\mathrm{RH}<5 \%$ are very rare. In the above case with $1 \% \mathrm{RH}$ the station was subsequently hit by the intrusion and exhibited not less than 13\% (10-min average). This kind of discrepancy has been meanwhile confirmed also by other lidar measurements that yielded 0 to $2 \%$ RH inside rather thin intrusion layers. This indicates a (varying) wet bias in the Zugspitze in-situ data of up to roughly $10 \% \mathrm{RH}$ under the dryest conditions. These aspects will be investigated further.

At this time, we tentatively conclude that that mixing with tropospheric air becomes less and less important as the air descends and as the velocity difference between the troposperic air and the intrusion becomes lower. The interesting observation that Type- 6 intrusions also frequently exhibit rather low humidities after a very long travel supports this view.

Here, we must add some caveat: Not all cases with Zugspitze RH values clearly above $10 \%$ mean strong mixing of the entire layer with tropospheric air. The Zugspitze station is not always ideally hit by the intrusions, in particular during the warm season (see results for Criterion 3). On sufficiently warm days the alpine boundary layer may reach considerable height (Carnuth and Trickl, 2000; Carnuth et al., 2002; Kreipl, 2006). This is hardened by lidar investigations during the past three years. In two cases very high ozone even far above $100 \mathrm{ppb}$ was observed just slightly above the station, but never reproduced there. In one case the stratospheric signature even completely disappeared at the summit during daytime and returned during the following night.

Due to this complexity the admixture of tropospheric air to stratospheric intrusions has not yet been included in the data filtering exercises for the Zugspitze data. Given the moderate variability of tropospheric ozone and the frequently low humidity in intrusion layers, the uncertainty caused by the choice of the threshold conditions has been regarded to be more important than the error caused by neglecting the tropospheric admixtures. On the way to a more and more refined approach also the complexity in the analysis of the in-situ measurements will grow and approaches based on the watervapour mixing ratio should be derived.

In any case, efforts for quantifying free-tropospheric mixing are highly desirable. Our own approach will include combined vertical sounding of water vapour and ozone, also hoping for better-resolved model calculations.
Acknowledgements. The authors thank A. Ebel, H. Davies, M. Kerschgens, and W. Seiler for their interest and support. T. Trickl appreciates the patience of his wife Heidi during that challenging (http://www.trickl.de) spring and summer of 2001. $H$. Claude made available the Hohenpeißenberg data for the relevant period in 2001 for comparison. M. Sprenger and H. Wernli thank MeteoSwiss for providing access to the ECMWF forecast data in real time. This work has been funded by the European Union within the STACCATO project as well as by the German Bundesministerium für Bildung und Forschung within the programme Atmosphärenforschung 2000 (ATMOFAST project).

Edited by: A. Volz-Thomas

\section{References}

Ancellet, G., Pelon, J., Beekmann, M., Papayannis, A., and Mégie, G.: Ground based lidar studies of ozone exchanges between the stratosphere and the troposphere, J. Geophys. Res., 96, 2240122421, 1991.

ATMOFAST: Atmosphärischer Ferntransport und seine Auswirkungen auf die Spurengaskonzentrationen in der freien Troposphäre über Mitteleuropa (Atmospheric Long-range Transport and its Impact on the Trace-gas Composition of the Free Troposphere over Central Europe), Project Final Report, Trickl, T., Co-ordinator, Kerschgens, M., Stohl, A., and Trickl, T., subproject co-ordinators, funded by the German Ministry of Education and Research within the programme “Atmosphärenforschung 2000", 130 pp., 2005.

Baray, J.-L., Daniel, V., Ancellet, G., and Legras, B.: Planetaryscale tropopause folds in the southern subtropics, Geophys. Res. Lett., 27, 353-356, 2000.

Beekmann, M., Ancellet, G., Blonsky, S., De Muer, D., Ebel, A., Elbern, H., Hendricks, J., Kowol, J., Mancier, C., Sladkovic, R., Smit, H. G. J., Speth, P., Trickl, T., and Van Haver, P.: Regional and Global Tropopause Fold Occurrence and Related Ozone Flux across the Tropopause, J. Atmos. Chem., 28, 29-44, 1997.

Bithell, M., Vaughan, G., and Gray, L. J.: Persistence of stratospheric ozone layers in the troposphere, Atmos. Environ., 34, 2563-2570, 2000.

Brioude, J., Cooper, O. R., Trainer, M., Ryerson, T. B., Holloway, J. S., Baynard, T., Peischl, J., Warneke, C., Neuman, J. A., De Gouw, J., Stohl, A., Eckhardt, S., Frost, G. J., McKeen, S. A., Hsie, E.-Y., Fehsenfeld, F. C., and Nédélec, P.: Mixing between a stratospheric intrusion and a biomass burning plume, Atmos. Chem. Phys., 7, 4229-4235, 2007, http://www.atmos-chem-phys.net/7/4229/2007/.

Browell, E. V., Danielsen, E. F., Ismail, S., Gregory, G. L., and Beck, S. M.: Tropopause Fold Structure Determined from Airborne Lidar and in Situ Measurements, J. Geophys. Res., 92, 2112-2120, 1987.

Carnuth, W. and Trickl, T.: Transport studies with the IFU threewavelength aerosol lidar during the VOTALP Mesolcina experiment, Atmos. Environ., 34, 1425-1434, 2000.

Carnuth, W., Kempfer, U., and Trickl, T.: Highlights of the Tropospheric Lidar Studies at IFU within the TOR Project, Tellus B., 54, 163-185, 2002.

Cho, J. Y. N., Newell, R. E., Browell, E. V., Grant, W. B., Butler, C. F., and Fenn, M. A.: Observation of pollution plume capping by 
a tropopause fold, Geophys. Res. Lett., 28, 3243-3246, 2001.

Cristofanelli, P., Bonasoni, P., Collins, W., Feichter, J., Forster, C., James, P., Kentarchos, A., Kubik, P. W., Land, C., Meloen, J., Roelofs, G. J., Siegmund, P., Sprenger, M., Schnabel, C., Stohl, A., Tobler, L., Tositti, L., Trickl, T., and Zanis, P.: Stratosphereto-troposphere transport: A model and method evaluation, J. Geophys. Res., 108, 8525, doi:10.1029/2002JD002600, 2003.

Cristofanelli, P., Bonasoni, P., Tositti, L., Bonafè, U., Calzolari, F., Evangelsti, F., Sandrini, S., and Stohl, A.: A 6-year analysis of stratospheric intrusions and their influence on the ozone at Mt. Cimone (2165 m above sea level), J. Geophys. Res., 111, D03306, doi:10.1029/20050JD006553, 2006.

Danielsen, E. F. and Mohnen, V. A.: Project Dustorm Report: Ozone Transport, in Situ Measurements, and Meteorological Analyses of Tropopause Folding, J. Geophys. Res., 82, 58675877, 1977.

Draxler, R. and Hess, G.: An overview of the HYSPLIT_4 modelling system for trajectories, dispersion, and deposition, Aust. Meteorol. Mag., 47, 295-308, 1998.

Ebel, A., Feldmann, H., Jakobs, H. J., Memmesheimer, M., Offermann, D., Kuell, V., and Schaeler, B.: Simulation of transport and composition changes during a blocking episode over the East Atlantic and North Europe, Ecol. Model., 217, 240-254, 2008.

Eisele, H. and Trickl, T.: Second Generation of the IFU Stationary Tropospheric Ozone Lidar, in: Advances in Atmospheric Remote Sensing with Lidar, Selected Papers of the 18th International Laser Radar Conference, Berlin (Germany), 22 to 26 July 1996, edited by: Ansmann, A., Neuber, R., Rairoux, P., and Wandinger, U., Springer, Berlin, Heidelberg, Germany, 379-382, 1997.

Eisele, H. and Trickl, T.: Improvements of the aerosol algorithm in ozone-lidar data processing by use of evolutionary strategies, Appl. Optics, 44, 2638-2651, 2005.

Eisele, H., Scheel, H. E., Sladkovic, R., and Trickl, T.: Highresolution Lidar Measurements of Stratosphere-troposphere Exchange, J. Atmos. Sci., 56, 319-330, 1999.

Elbern, H., Kowol, J., Sladkovic, R., and Ebel, A.: Deep stratospheric intrusions: A statistical assessment with model guided analysis, Atmos. Environ., 31, 3207-3226, 1997.

Flentje, H., Dörnbrack, A., Ehret, G., Fix, A., Kiemle, C., Poberaj, G., and Wirth, M.: Water vapor heterogeneity related to tropopause folds over the North Atlantic revealed by airborne water vapor differential absorption lidar, J. Geophys. Res., 110, D03115, doi:10.1029/2004JD004957, 2005.

Galani, E., Balis, D., Zanis, P., Zerefos, C., Papayannis, A., Wernli, H., and Gerasopoulos, E.: Observations of stratosphereto-troposphere transport events over the eastern Mediterranean using a ground-based lidar system, J. Geophys. Res., 108, 8527, doi:10.1029/2002JD002596, 2003.

Gerasopoulos, E., Zerefos, C. S., Papastefanou, C., Zanis, P., and O'Brien, K.: Low-frequency variability of beryllium-7 surface concentrations over the Eastern Mediterranean, Atmos. Environ, 37, 1745-1756, 2003.

Grant, W. B., Browell, E. V., Butler, C. F., Fenn, M. A., Clayton, M. B., Hannan, J. R., Fuelberg, H. E., Blake, D. R., Blake, N. J., Gregory, G. L., Heikes, B. G., Sachse, G. W., Singh, H. B., Snow, J., and Talbot, R. W.: A case study of transport of tropical marine boundary layer and lower tropospheric air masses to the northern midlatitude upper troposphere, J. Geophys. Res., 105, 3757-3769, 2000.
Grell, G., Duddhia, J., and Staufer, D.: A description of the fifthgeneration Penn State/Ncar meso-scale model (MM5), Technical note NCAR/TN-398+STR, National Center of Atmospheric Research, Boulder, USA, 122 pp., 1994.

Hass, H., Ebel, A., Feldmann, H., Jakobs, H. J., and Memmesheimer, M.: Evaluation studies with a regional chemical transport model (EURAD) using air quality data from the EMEP monitoring network, Atmos. Environ., 27A, 867-887, 1993.

Holton, J. R., Douglass, A. R., Haynes, P. H., McIntyre, M. E., Rood, R. B., and Pfister, L.: Stratosphere-troposphere exchange, Rev. Geophys., 33, 403-439, 1996.

Koch, D. M. and Mann, M. E.: Spatial and temporal variability of ${ }^{7}$ Be surface concentrations, Tellus B, 48, 387-396, 1996.

Koch, P., Wernli, H., and Davies, H. C.: An event-based jet-stream climatology and typology, Int. J. Climatol., 26, 283-301, 2006.

Kowol-Santen, J., Elbern, H., and Ebel, A.: Estimation of crosstropopause air mass fluxes at midlatitudes: Comparison of different numerical methods and meteorological situations, Mon. Weather Rev., 128, 4045-4057, 2000.

Kreipl, S.: Messung des Aerosoltransports am Alpennordrand mittels Laserradar (Lidar), Dissertation zur Erlangung des Doktorgrads, Universität Erlangen (Germany), 195 pp., 2005.

Lal, D. and Peters, B.: Cosmic ray produced radioactivity on the earth, Handb. Phys., 46, 551-612, 1967.

Langford, A. O., Masters, C. D., Proffitt, M. H., Hsie, E. Y., and Tuck, A. F.: Ozone measurements in a tropopause fold associated with a cut-off low system, Geophys. Res. Lett., 23, 2501-2504, 1996.

Meloen, J., Siegmund, P., van Velthoven, P., Kelder, H., Sprenger, M., Wernli, H., Kentarchos, A., Roelofs, G., Feichter, J., Land, C., Forster, C., James, P., Stohl, A., Collins, W., and Crstofanelli, P.: Stratosphere-troposphere exchange: A model and method intercomparison, J. Geophys. Res., 108, 8526, doi:10.1029/2002JD002274, 2003.

Memmesheimer, M., Tippke, J., Ebel, A., Hass, H., Jakobs, H. J., and Laube, M.: On the use of EMEP emission inventories for European scale air pollution modeling with the EURAD model, in: Proceedings of the EMEP workshop on Photooxidant Modelling for Long-Range Transport in Relation to Abatement Strategies, Berlin, Germany, 16-19 April, 307-324, 1991.

Oltmans, S. J., Lefohn, A. S., Harris, J. M., Galbally, I., Scheel, H. E., Bodeker, G., Brunke, E., Claude, H., Tarasick, D., Johnson, B. J., Simmonds, P., Shadwick, D., Anlauf, K., Hayden, K., Schmidlin, F., Fujimoto, F., Akagi, K., Meyer, C., Nichol, S., Davies, J., Redondas, A., and Cuevas, E.: Long-term changes in tropospheric ozone, Atmos. Environ., 40, 3156-3173, 2006.

Papayannis, A., Balis, D., Zanis, P., Galani, E., Wernli, H., Zerefos, C., Stohl, A., Eckhardt, S., and Amiridis, V.: Sampling of an STT event over the Eastern Mediterranean region by lidar and electrochemical sonde, Ann. Geophys., 23, 2039-2050, 2005, http://www.ann-geophys.net/23/2039/2005/.

Parrish, D. D., Holloway, J. S., Jakoubek, R., Trainer, M., Ryerson, T. B., Hübler, G., Fehsenfeld, F. C., Moody, J. L., and Cooper, O. C.: Mixing of anthropogenic pollution with stratospheric ozone: A case study from the North Atlantic wintertime troposphere, J. Geophys. Res., 105, 24363-24374, 2000.

Pötzl, K. and Carnuth, W.: Isolierung und Identifizierung des atmosphärischen ${ }^{7} \mathrm{Be}$, Radiochim. Acta, 6, 133-135, 1966. 
Ravetta, F., Ancellet, G., Kowol-Santen, J., Wilson, R., and Nedeljkovic, D.: Ozone, Temperature and Wind Field Measurements in a Tropopause Fold: Comparison with a Mesoscale Model Simulation, Mon. Weather Rev., 127, 2641-2653, 1999.

Reiter, R., Sladkovic, R., Pötzl, K., Carnuth, W., and Kanter, H.-J.: Studies on the Influx of Stratospheric Air into the Lower Troposphere Using Cosmic-Ray Radionuclides and Fallout, Arch. Meteor. Geophy. A., 20, 211-246, 1971.

Reiter, R., Munzert, K., Kanter, H.-J., and Pötzl, K.: Cosmogenic Radionuclides and Ozone at a Mountain Station at $3.0 \mathrm{~km}$ a.s.1., Arch. Meteor. Geophy. B., 32, 131-160, 1983.

Reiter, R., Sladkovic, R., and Kanter, H.-J.: Concentration of Trace Gases in the Lower Troposphere, Simultaneously Recorded at Neighboring Mountain Stations, Part II: Ozone, Meteorol. Atmos. Phys., 37, 27-47, 1987.

Roelofs, G.-J. and Lelieveld, J.: Model study of the influence of cross-tropopause $\mathrm{O}_{3}$ transports on tropospheric $\mathrm{O}_{3}$ levels, Tellus B, 49, 38-55, 1997.

Roelofs, G. J., Kentarchos, A. S., Trickl, T., Stohl, A., Collins, W. J., Crowther, R. A., Hauglustaine, D., Klonecki, A., Law, K. S., Lawrence, M. G., von Kuhlmann, R., and van Weele, M.: Intercomparison of tropospheric ozone models: Ozone transport in a complex tropopause folding event, J. Geophys. Res., 108, 8529, doi:10.1029/2003JD003462, 2003.

Scheel, H. E. and Kanter, H.-J.: Measurements of $\mathrm{O}_{3},{ }^{7} \mathrm{Be}, \mathrm{RH}$ and $\mathrm{CO}$ at the Zugspitze summit, in: EUROTRAC - Influence of Stratosphere-Troposphere Exchange in a Changing Climate on Atmospheric Transport and Oxidation Capacity, Final Report, Contract EVK2-CT-1999-00050, Stohl, A., Coordinator, European Union, 58-62, available at: http://www. forst.tu-muenchen.de/EXT/LST/METEO/staccato/, last access: January 2010, 2002.

Scheel, H. E.: Ozone Climatology Studies for the Zugspitze and Neighbouring Sites in the German Alps, in: Tropospheric Ozone Research 2, EUROTRAC-2 Subproject Final Report, Lindskog, A., Co-ordinator, EUROTRAC International Scientific Secretariat, München, Germany, 134-139, 2003.

Scheel, H. E., Areskoug, H., Geiß, H., Gomiscek, B., Granby, K., Haszpra, L., Klasinc, L., Kley, D., Laurila, T., Lindskog, A., Roemer, M., Schmitt, R., Simmonds, P., Solberg, S., and Toupance, G.: On the Spatial Distribution and Seasonal Variation of Lower-Tropospheric Ozone over Europe, J. Atmos. Chem., 28, 11-28, 1997.

Seibert, P., Feldmann, H., Neininger, B., Bäumle, M., and Trickl, T.: South foehn and ozone in the Eastern Alps - case study and climatological aspect, Atmos. Environ., 34, 1379-1394, 2000.

Shapiro, M. A.: Turbulent Mixing within Tropopause Folds as a Mechanism for the Exchange of Chemical Constituents between the Stratosphere and Troposphere, J. Atmos. Sci., 37, 994-1004, 1980.

Simmonds, P. G., Derwent, R. G., Manning, A. L., and Spain, G.: Significant growth in surface ozone at Mace Head, Ireland, 1987-2003, Atmos. Environ., 38, 4769-4778, 2004.

Sladkovic, R. and Munzert, K.: Lufthygienisch-klimatologische Überwachung im bayrischen Alpenraum, Abschnitt VI.4, Ozonspitzen auf der Zugspitze durch Zustrom aus der Stratosphäre, Final Report, Fraunhofer-Institut für Atmosphärische Umweltforschung, Report 908080, 49-50, 1990.
Sprenger, M., Croci Maspoli, M., and Wernli, H.: Tropopause folds and cross-tropopause exchange: A global investigation based upon ECMWF analyses for the time period March 2000 to February 2001, J. Geophys. Res., 108, 8518, doi:10.1029/2002JD002587, 2003.

STACCATO: Special section with 15 publications, J. Geophys. Res., 108(D12), papers STA 1-15, 27 June, 2003.

Stohl, A. and Seibert, P.: Accuracy of trajectories as determined from the conservation of meteorological tracers, Q. J. Roy. Meteor. Soc., 124, 1465-1484, 1998.

Stohl, A. and Thomson, D. J.: A density correction for Lagrangian particle dispersion models, Bound.-Lay. Meteorol., 90, 155-167, 1999.

Stohl, A. and Trickl, T.: A textbook example of long-range transport: Simultaneous observation of ozone maxima of stratospheric and North American origin in the free troposphere over Europe, J. Geophys. Res., 104, 30445-30462, 1999.

Stohl, A., Spichtinger-Rakowsky, N., Bonasoni, P., Feldmann, H., Memmesheimer, M., Scheel, H. E., Trickl, T., Hübener, S., Ringer, W., and Mandl, M.: The influence of stratospheric intrusions on alpine ozone concentrations, Atmos. Environ., 34, 1323-1354, 2000.

Stohl, A., Eckhardt, S., Forster, C., James, P., Spichtinger, N., and Seibert, P.: A replacement for simple back trajectory calculations in the interpretation of atmospheric trace substance measurements, Atmos. Environ., 36, 4635-4648, 2002.

Stohl, A., Bonasoni, P., Cristofanelli, P., Collins, W., Feichter, J., Frank, A., Forster, C., Gerasopoulos, E., Gäggeler, H., James, P., Kentarchos, T., Kromp-Kolb, H., Krüger, B., Land, C., Meloen, J., Papayannis, A., Priller, A., Seibert, P., Sprenger, M., Roelofs, G. J., Scheel, H. E., Schnabel, C., Siegmund, P., Tobler, L., Trickl, T., Wernli, H., Wirth, V., Zanis, P., and Zerefos, C.: Stratosphere-troposphere exchange - a review, and what we have learned from STACCATO, J. Geophys. Res., 108, 8516, doi:10.1029/2002JD002490, 2003.

Stohl, A., Forster, C., Frank, A., Seibert, P., and Wotawa, G.: Technical note: The Lagrangian particle dispersion model FLEXPART version 6.2, Atmos. Chem. Phys., 5, 2461-2474, 2005, http://www.atmos-chem-phys.net/5/2461/2005/.

Tositti, L., Hübener, S., Kanter, H.-J., Ringer, W., Sandrini, S., and Tobler, L.: Intercomparison of sampling and measurements of ${ }^{7} \mathrm{Be}$ in air at four high altitude locations in Europe, Appl. Radiat. Isotopes, 61, 1497-1502, 2004.

Trickl, T., Cooper, O. C., Eisele, H., James, P., Mücke, R., and Stohl, A.: Intercontinental transport and its influence on the ozone concentrations over central Europe: Three case studies, J. Geophys. Res., 108, 8530, doi:10.1029/2002JD002735, 2003.

Trickl, T., Bärtsch-Ritter, N., Eisele, H., Furger, M., Mücke, R., and Stohl, A.: High-ozone layers in the middle and upper troposphere above Central Europe: strong import from the stratosphere over the Pacific Ocean, Atmos. Chem. Phys. Discuss., 9, 3113-3166, 2009, http://www.atmos-chem-phys-discuss.net/9/3113/2009/.

Trickl, T., Forster, C., Scheel, H. E., and Stohl, A.: Low Ozone and Carbon Monoxide in Air Masses from the Subtropical North Atlantic, in preparation, 2010.

Van Haver, P., De Muer, D., Beekmann, M., and Mancier, C.: Climatology of tropopause folds at midlatitudes, Geophys. Res. Lett., 23, 1033-1036, 1996. 
Viezee, W., Johnson, W. B., and Singh, H. B.: Stratospheric Ozone in the Lower Troposphere - II. Assessment of Downward Flux and Ground-Level Impact, Atmos. Environ., 17, 1979-1993, 1983.

Vogelmann, H. and Trickl, T.: Wide-Range Sounding of FreeTropospheric Water Vapor with a Differential-Absorption Lidar (DIAL) at a High-Altitude Station, Appl. Optics, 47, 2116-2132, 2008.

VOTALP: Vertical Ozone Transport in the Alps, special section with nine publications, Atmos. Environ., 34, 1319-1453, 2000a.

VOTALP II: Vertical Ozone Transport in the Alps II, Final Report for the European Union, Contract Nr.: ENV4 CT970413, Reporting Period 1/3/1998-29/2/2000, Kromp-Kolb, H., Co-ordinator, Universität für Bodenkultur Wien, Austria, Institut für Meteorologie und Physik, available at: http://www.boku.ac.at/imp/ votalp/, last access: January 2010, 2000 b.

Wernli, H. and Davies, H. C.: A Lagrangian-based analysis of extratropical cyclones, I. The method and some applications, 123, 467-489, 1997.
Wernli, H.: A Lagrangian-based analysis of extratropical cyclones, II: A detailed case study, Q. J. Roy. Meteor. Soc., 123, 16771706, 1997.

Zanis, P., Trickl, T., Stohl, A., Wernli, H., Cooper, O., Zerefos, C., Gaeggeler, H., Schnabel, C., Tobler, L., Kubik, P. W., Priller, A., Scheel, H. E., Kanter, H. J., Cristofanelli, P., Forster, C., James, P., Gerasopoulos, E., Delcloo, A., Papayannis, A., and Claude, H.: Forecast, observation and modelling of a deep stratospheric intrusion event over Europe, Atmos. Chem. Phys., 3, 763-777, 2003, http://www.atmos-chem-phys.net/3/763/2003/.

Zanis, P., Gerasopoulos, E., Priller, A., Schnabel, C., Stohl, A., Zerefos, C., Gäggeler, H. W., Tobler, L., Kubik, P. W., Kanter, H. J., Scheel, H. E., Luterbacher, J., and Berger, M.: An estimate of the impact of stratosphere-to-troposphere transport (STT) on the lower free tropospheric ozone over the Alps using ${ }^{10} \mathrm{Be}$ and ${ }^{7} \mathrm{Be}$ measurements, J. Geophys. Res., 108, 8520, doi:10.1029/2002JD002604, 2003a. 